\title{
"We're Just Geeks": Disciplinary Identifications Among Business Students and Their Implications for Personal Responsibility
}

\author{
Maribel Blasco ${ }^{1}$ (D)
}

Received: 13 July 2019 / Accepted: 27 January 2021 / Published online: 25 February 2021

(c) The Author(s) 2021

\begin{abstract}
This research shows how business students' disciplinary specializations can affect their sense of personal responsibility by providing rationalizations for moral disengagement. It thereby conceptualizes business students' disciplinary specializations as a key dimension of the business school responsibility learning environment. Students use four main rationalizations to displace responsibility variously away from their own disciplinary specializations, to claim responsibility as the prerogative of their specialization, and to shift irresponsibility onto disciplinary out-groups. Yet despite their disciplinary identifications, students largely rationalized that their sense of responsibility was an individual matter that was unlikely to be affected by contextual influences, and they attributed irresponsible behavior to incorrigible 'bad apples.' A theoretical model is offered which illustrates these dynamics by combining Bandura's social cognitive theory with social identity theory. The research is based on secondary data, specifically focus-group interviews conducted with undergraduate students at a major Scandinavian business school in connection with the implementation of the UN Principles for Responsible Management Education (PRME) initiative. The implications for management education include the need to strengthen students' 'disciplinary reflexivity,' and to explicitly address the tension between students' disciplinary solidarities and their faith in their own individual moral infallibility.
\end{abstract}

Keywords Moral disengagement $\cdot$ Moral reasoning $\cdot$ Personal responsibility $\cdot$ Disciplines $\cdot$ Business students $\cdot$ Management education

\section{Introduction}

One of the most disturbing features of major corporate scandals of recent decades was how both managers and employees with previously impeccable reputations turned a blind eye or even became a party to deeply unethical practices. Studies reveal how participants succumbed to contextual and social pressures, derogated their personal moral responsibility to their corporations, and then found rationalizations to justify their behavior (Becker 2018; Treviño and Nelson 2016; Riordan and Riordan 2013; Barsky 2011; Hawtree and Johnson 2010; Robinson 2009; Bansal and Kandola 2003; Sims and Brinkmann 2003). This phenomenon, whereby individuals find rationalizations to exempt themselves from

Maribel Blasco

mbl.msc@cbs.dk

1 Department of Management, Society \& Communication, Copenhagen Business School, Dalgas Have 15, 2000 Frederiksberg, Denmark personal responsibility, is known as 'moral disengagement' (MD) (Bandura et al. 1996) and remains a major challenge in the drive to combat unethical business behavior (Riordan and Riordan 2013; Baker et al. 2006). It is also a major predictor of future unethical behavior more generally (Farnese et al. 2011; Detert et al. 2008). Understanding how people rationalize about personal responsibility is therefore central in countering unethical business activity and, more broadly, in understanding moral reasoning (De los Reyes et al. 2017, p. 325), that is, "the process by which people determine that one course of action in a particular situation is morally right and another course of action is wrong" (Rest et al. 1997, p. $5)$.

Since "today's college students represent tomorrow's leaders" (McCabe et al. 2012, p. 3; Haski-Leventhal et al. 2017), and higher education is known to be important for future employees' moral development (Hummel et al. 2018; McCabe et al. 2012), understanding how business students rationalize about their personal responsibility is important in illuminating the under-explored link between what goes 
on at business schools and corporate irresponsibility (Frederick and Swanson 2017; Felton and Sims 2005). It is also vital in detecting possible antecedents of MD among business students at an early stage. A strong sense of personal responsibility is considered crucial in deterring business scandals (Robinson and Murphy 2009); however, business schools have faced persistent critiques that they bear some of the blame for those scandals by failing to prepare students adequately for the moral challenges that they will face in the business world (Laasch 2018; Parker 2018; Koris et al. 2017; Foray et al. 2015; Hanson and Moore 2014; Moosmayer 2012; Caldwell 2010; Giacalone and Thompson 2006; Ghoshal 2003, 2005; Grey 2002; though see Neubaum et al. 2009).

Concern has been raised specifically about business students' moral reasoning (McPhail and Walters 2009), with studies showing that business students are more likely than other students to find ready rationalizations for their actions, and that "questionable ethical behavior ... is more prevalent in business schools than in all other academic institutions" (Koris et al. 2017, p. 175; Lampe and Engleman-Lampe 2012; McCabe et al. 2012; Klein et al. 2007; McCabe and Treviño 1995). While some posit that students' moral character is already formed before they arrive at business school, or that some individuals are simply inherently corruptthe so-called bad apple notion-others hold that business schools may negatively impact students' sense of responsibility in various ways - the 'bad barrel' thesis (Baker et al. 2006). This is thought to occur, for instance, through the 'amoral theories' taught, a narrow focus on shareholder maximization (Ghoshal 2005; Mitroff 2004) and neoliberal orthodoxy (McIntosh 2017), insufficient emphasis on critical thinking (Antonacopoulou 2010), and the implicit messages conveyed through the so-called hidden curriculum (Blasco 2012, 2018; 2020; Ehrensal 2001).

In this article, I present findings and a theoretical framework resulting from an exploratory study carried out at a major Scandinavian business school (SBS), showing that a so far little studied aspect of business school learning environments, namely business students' perceptions of, and identifications with, disciplinary specializations, can be detrimental to their sense of personal responsibility by providing them with rationalizations for moral disengagement (Bandura et al. 1996; Bivins 2006). A sense of personal responsibility is usually thought to be supported by a strong professional identity (Thomson and Jones 2017; Trede et al. 2012), and hence, considerable efforts are devoted at business schools to strengthening these aspects in the different business specializations through various pedagogical techniques (Glaser-Segura et al. 2010) that expose students to socialization that crafts their "sense of identity as a particular type of professional" (Colbeck 2008, p. 9) and train them in specific professional and organizational tools and theories, norms, and standards that shape their perceptions of responsibility (Gröschl and Gabaldon 2018; Thomson and Jones 2017; Thomas 2012; Trede et al. 2012; Wallerstein et al. 2003; Becher and Trowler 2001). Subsequent failures to live up to such standards are often attributed to "bad apples" (Treviño and Nelson 2016, p. 13). Yet professional identities can be based on quite narrow conceptions of responsibility, and can foster in-group solidarities which may not always be conducive to the exercise of individual responsibility - indeed, professionals often rationalize their behavior by recourse to the requirements of their professional roles, and may never question the moral rightness of those roles (Robinson 2009; Bivins 2006).

The study offers two main contributions. First, it provides novel empirical insights into how business students rationalize about their responsibility in relation to disciplinary specializations - to date, much research on responsible management education has tended to neglect students' own voices about responsibility, casting them as passive learners or investigating their unethical attitudes and behavior, such as cheating (HaskiLeventhal et al. 2017; Klein et al.2007). Second, it offers a model that theorizes how students' perceptions of, and identifications with, disciplinary specializations can work against their sense of personal responsibility by providing them with a priori rationalizations for moral disengagement. The study contributes to scholarship on responsible management education by highlighting that students' perceptions of disciplinary specializations constitute important aspects of the responsibility learning environment at business schools, which is currently an understudied area (Baker 2014).

The study is based on a pre-existing dataset generated through focus-group interviews conducted with undergraduate business students from different disciplinary specializations about their views on what it means to be 'responsible.' The focus-group interviews were conducted in connection with the UN Principles for Responsible Management Education (PRME) implementation at the school in question. The research question was: Do students' rationalizations about their disciplinary specializations have implications for their sense of personal responsibility, and if so how does this work? The paper is structured as follows. First, I review literature on moral reasoning and disengagement, and then I explore how this can be linked to disciplinary identifications using insights from social identity theory. I then present the methodology, followed by the data analysis and a discussion of the findings.

\section{Moral Reasoning, Personal Responsibility and Moral Disengagement}

Moral reasoning - the process through which an individual decides what is right or wrong and justifies their thinking- is a key step in ethical decision-making (Rest 1986). It also 
underpins personal responsibility, defined as individuals assuming ownership of their thoughts, beliefs, and actions and accepting responsibility for these (Hiemstra 1994; Brockett and Hiemstra 1991). Scholars have debated whether moral reasoning is shaped by social context or by individuals' stage of moral development. Socialization approaches to moral reasoning hold that undesirable behaviors are regulated by internalized social norms, such as cultural values (Bian et al. 2019; Chiu et al. 2000; Narvaez et al. 1999; Miller and Bersoff 1992), gender norms (Walker 2014; Gilligan 1982), and formal education (Nather 2013; Doyle and O'Flaherty 2013). If an individual violates these internalized norms, this gives rise to emotions such as guilt and shame (Johnson and Connelly 2016; Blair and Fowler 2008). In contrast, cognitive developmental models hold that individuals' moral reasoning progresses with age through a series of cognitive stages (Piaget 1932; Sonnert and Commons 1992; Kohlberg 1969). In Kohlberg's influential model, for instance, people's moral reasoning and decision-making become more autonomous as they pass through three stages of moral development (Rajeev 2011; Treviño and McCabe 1994). The first stage, the pre-conventional level, pertains to children, who have no personal moral code-rather, their morality is controlled by external influences such as rules, laws or significant others. In the second stage, the conventional level, morality is still shaped by such external prescripts, but these are now internalized as personal beliefs in the 'right thing to do.' In the third stage, the post-conventional level, individuals become able to reason independently from, and question, such societal prescripts (Rajeev 2011; Treviño and McCabe 1994).

Both models have been questioned: the first notably because individuals' behavior is not always aligned with their internalized norms and values (Schein 2010); and the second because most adults never actually reach the stage of moral autonomy or may deliberately choose to reason at a lower level than they have attained (Sykes and Matza 1957; Minnameier 2014). Moreover, it is today widely acknowledged that moral reasoning is often situation specific (Minnameier 2014); that it may be affected by the nature of the issue at stake (Jones 1991; Walker 1989; Walker et al. 1987; Wark and Krebs 1997), and that it often remains susceptible to external influences such as incentives and rules, relationships, and social pressures (Bandura 2016; Thomson and Jones 2017; Baker 2014; Rajeev 2011; Cunliffe and Eriksen 2011; Narvaez 1999; Card 2005; Bansal and Kandola 2003; Treviño and Nelson 1999; McNamee and Gergen 1999a, b, Jones 1991).

\section{Moral Disengagement}

Bandura's social cognitive theory (SCT) sits between the two above-mentioned approaches, proposing an interactionist view of moral agency as a result of "the reciprocal interplay of personal and social influences" (Bandura 1999, p. 207; Baker et al. 2006). According to SCT, moral standards internalized during socialization are thought to serve as "guides and deterrents for action" (Bandura et al. 1996, p. 364). If faced with situational inducements to behave irresponsibly, people exercise their moral agency through self-regulatory mechanisms that usually prevent them from acting in ways that violate their own moral standards, as this leads to selfcensure; if tempted, "anticipatory self-sanctions" are applied to keep themselves in line (Bandura 1999, p. 194).

However, Bandura found that in certain situations, individuals may selectively deactivate their own moral standards - a maneuver he termed 'moral disengagement' (MD) - using various rationalizations that enable them to reconstrue reprehensible behaviors as righteous, thereby downplaying their sense of personal responsibility (Bandura et al. 1996). These rationalizations allow individuals to decouple their behavior from their own internal standards without experiencing distress (Moore 2015). MD increases the chance of unethical behavior occurring because it "disconnects a contemplated act from the guilt or self-censure that would otherwise prevent it" (Detert et al. 2008, p. 378). Bandura's theory of MD has therefore been used to shed light on a wide range of deviant behaviors (see overview in Kavussanu 2008), including corporate social irresponsibility (White et al. 2009; Bandura et al. 2000), unethical behavior in organizations (Treviño et al. 2006; Moore et al. 2012), and corruption (Moore 2008).

Bandura identified eight interconnected cognitive strategies that individuals use to deactivate their personal responsibility, three of which have particular relevance to this study. The first, displacement of responsibility, involves minimizing one's role as the agent of one's own actions, for instance by regarding these as resulting from the "dictates of authorities" (Bandura 1999, p. 365). The second, diffusion of responsibility, involves a "division of labor" that muddies the picture regarding responsibility, for instance by detaching sub-functions in an organization from one another, so that people "shift their attention from the morality of what they are doing to the operational details and efficiency of their specific job" (Bandura 1999, p. 198). The third, dehumanization, involves divesting one's adversaries of their human properties or casting them as bad people, making it easier to mistreat them or blame them for wrongdoing (Bandura 1999). The remaining five disengagement strategies, which will not be addressed further here, are as follows: disregard or distortion of the consequences of one's actions; attribution of blame, which involves blaming circumstances or one's foes, while exonerating oneself from blame; euphemistic labeling, involving giving a behavior a more palatable name; moral justification, which means reconstruing immoral behavior so that it appears to serve a moral purpose; 
and advantageous comparison, where people justify their own behavior by comparing it with examples of even worse behavior (Bandura et al. 1996, pp. 199-200; Moore 2015).

Research has shown that the propensity to morally disengage may be exacerbated by a number of factors, such as gender, with males generally more prone to MD than females (McAlister et al. 2006; Bandura et al. 1996); age, with the propensity to MD decreasing at adolescence (Paciello et al. 2008); religious belief and ethnicity (McAlister et al. 2006); as well as by individual traits such as empathy, sympathy, cynicism and social dominance orientation (Detert et al. 2008; Baker et al. 2006). Specifically business students have been found to display various characteristics that predispose them to MD upon admission to business school, notably low levels of chance locus of control (the extent to which they see life events as beyond their own control) and moral identity (the salience of a person's moral identity to their sense of self); and high scores on trait cynicism and social dominance (Baker et al. 2006).

Contextual influences, such as home environment and neighborhood (Moore 2015), social influence, and attachments to in-groups and close others, have also been found to increase individuals' propensity towards MD, by causing them to feel less personal responsibility for decisions (Moore 2015; Bandura 1999; Zimbardo 1995) and by facilitating dehumanization of others perceived as more distant (Waytz and Epley 2012; Bandura 1999). Studies of Nazi prison staff and others who have committed atrocities illustrate the powerful effects of such influences on people's sense of personal responsibility (Bandura 1999), as do social-psychological experiments such as Zimbardo's (2007) Stanford Prison study and Milgram's $(1963,1974)$ obedience study, which show how ordinary people can commit inhumane acts by ceding their personal responsibility to their assigned roles, to seemingly legitimate authorities, and to group pressures to conform. And in corporations, collective MD can result from group members "acting together on shared beliefs," with different groups of actors finding ways to "neutralize the moral implications of their role in their organization's products and practices [providing] exonerations for each other" (White et al. 2009, p. 43).

Bandura's research on MD paints a more complex picture of the relationship between personal responsibility, moral reasoning, and social and contextual influences than proposed either in socialization- or age-based models of moral development. Notably, he draws attention to how contextual influences may have deleterious, rather than regulating, effects on individuals' moral reasoning, providing them with justifications for moral disengagement. His work further shows how moral autonomy is not necessarily a desirable end goal if it is exercised as a decision to disengage one's internalized moral standards in order to conform to authority or to group influences. However, theoretical insights are needed into why individuals may elect to morally disengage, notably, in this case, into why disciplinary identifications seem, in some cases, to trigger the three MD mechanisms mentioned above, namely dehumanization, displacement, and diffusion of responsibility. I argue in the following section that social identity theory can shed light on this through its conceptualization of how powerful group identifications may lead a person to disengage his or her individual identity and subsume it to that of a group, with implications for their sense of personal responsibility.

\section{Social Identification and Moral Disengagement}

While scholars continue to debate the extent to which people have an essential stable or core identity (Hyland 2012), it is generally agreed that an individual's identity is composed of, and performed through, identifications with various groups (Brubaker 2004; Ashforth and Mael 1989). Turner (1982, pp. 17-18) defines social identification as "the process of locating oneself, or another person, within a system of social categorizations or to any social categorization used by a person to define him- or herself or others." Group belongings have value and powerful emotional significance for individuals (Tajfel 1972, p. 292).

Group members use prototypes-fuzzy sets of attributes such as attitudes and behaviors - to represent both in- and out-groups (Hogg and Reid 2006, p. 10), that is, those who resemble and differ from themselves, respectively (Stets and Burke 2000). These prototypes prescribe "what kinds of attitudes, emotions and behaviors are appropriate in a given context" (Hornsey 2008, p. 209). Through this self-categorization, group members emphasize perceived similarities in these aspects between themselves and other in-group members, and accentuate perceived differences between themselves and out-group members (Stets and Burke 2000). Group representations - for instance about disciplinesthereby become "inextricable from group comparisons" (Hogg and Reid 2006, p. 10), which are used to maintain social identities (Jenkins 2014; Hogg and Reid 2006; Turner 1982), and (usually) to emphasize own positive differences compared to reference groups (Turner 1982, p. 21; Jenkins 2014). As Czarniawska (2008) notes, identity construction necessarily involves alterity construction, that is, constructing one's own identity as different from an 'other' in terms of 'us' and 'them' (see also Lawler 2008). Such in-group preferences and competitive behavior towards out-groups are thought to be motivated by individuals' desire to maintain a positive self-concept through identification with their ingroup (Hornsey 2008).

Social identity may also override personal identity, that is, "specific attributes of the individual" in certain situations 
(Turner 1982, p. 18; Stets and Burke 2000), so that individual group members' self-perception is subsumed to the in-group prototype, causing them to see themselves "less as individuals and more as interchangeable exemplars of the group prototype"-a phenomenon known as "depersonalization" (Hornsey 2008, p. 208). This results in that person's "thoughts, feelings, perceptions, and behavior" conforming to that prototype (Hogg and Reid 2006, p. 11). Research on the link between personal and social responsibility in higher education, for instance, shows that individual students' values, beliefs, and aspirations tend to converge with those dominant within their student peer groups, which constitute the strongest influence on their growth and development during their undergraduate years (Astin 1993 in Swaner 2005, p. 17). Depersonalization does not entail a loss of personal identity, just a "contextual change in levels of identity (from unique individual to group member) ... that transforms individuals into group members and individuality into group behavior" (Hogg et al. 1995, p. 261).

Below, I explain how professional disciplinary specializations can constitute in-groups with which individuals identify, thereby both triggering depersonalization and constituting out-groups that are regarded as 'other.'

\section{Disciplines, Professional Identity Formation and Responsibility}

As indicated above, a robust professional identity is usually considered essential in assuring responsible professional behavior. Following Crigger and Godfrey's (2014, p. 377) definition, professional identity consists of "an individual's perception of himself or herself, who, as a member of a profession, has responsibilities to society, recipients of care, other professionals, and to himself or herself"; hence, the notion of responsibility is closely tied to identification with a professional group. Although professional identity formation continues after graduation and throughout people's careers, its foundations are lain during students' undergraduate years, which are generally agreed to be crucial for their moral development and future professional integrity (Crigger and Godfrey 2014, p. 377). Disciplinary specializations are generally regarded as the precursors of their corresponding professional specializations (Gröschl and Gabaldon 2018; Becher and Trowler 2001), and as the means through which students begin to develop a sense of professional identity. In a successful professionalization process, students' personal, non-professional identity is broken down and replaced or integrated with a 'professional ideology,' resulting in a 'radical change in self-identity' whereby they begin to identify with their profession and it becomes part of their identity (Crigger and Godfrey 2014, p. 377; Minnameier 2014; Trede et al. 2012; West and Chur-Hansen 2004).
Professionalization processes are usually described in terms of two main dimensions. First, students are socialized, through their disciplinary specializations, into particular mental models, or "cognitive representations of external reality," which are used to explain and anticipate things, and which include shared knowledge and skill sets, ethical guidelines and principles, values, standards, and codes of conduct (Jones et al. 2011, p. 1; Becher and Trowler 2001). At business schools, as elsewhere, disciplinary mental models are often broadly classified in terms of the epistemological dichotomy between 'hard' and 'soft' disciplines (Biglan 1973). 'Hard' disciplines are characterized by a belief in unambiguous, scientific knowledge, and in their ability to predict and control the object of study, compared to 'soft' disciplines which emphasize complexity and ambiguity, a distinction that shapes students' beliefs about knowledge (Schommer-Aikins et al. 2003). Biglan (1973) further distinguishes between 'pure' disciplines such as mathematics, which focus on theory building, and 'applied' disciplines such as education, which focus on theory application and practice; and between 'life' disciplines that focus on living or organic phenomena compared to 'non-life' disciplines which study non-biological phenomena. As an academic field, business studies encompasses both 'hard' and 'pure' disciplines like statistics, and 'softer,' more 'applied' disciplines like sociology, with many specializations such as marketing combining both (Macfarlane 1995).

Biglan's typology of disciplines, though widely used, has met with considerable critique due, inter alia, to its overgeneralization and overlooking of internal differences within disciplines (Trowler 2014), and its failure to take account of contextual factors as well as personal identities and perceptions (including critical ones) in perceptions of own disciplines (Fanghanel 2009). Biglan's typology has also come to carry normative connotations, with harder, purer disciplines tending to be deemed more 'masculine' and prestigious than those at the soft-applied end of the scale (Macfarlane 1995; Archer and Freedman 1989). They may also be deemed more scientific - a distinction that affects both the relative presence of men and women in the respective disciplines, and "their power outside their boundaries," for instance, promotion opportunities and the availability of resources (Kogan 2005, p. 18; White et al. 2011; Xu 2008; Kulis et al. 2002). Accordingly, disciplinary specializations are more than just cognitive schema involving particular knowledge and skill sets-they also represent normative views about knowledge that feature "axioms and simplifications" (Khurana and Spender 2012, p. 629) that structure-and can warp-how they frame reality (Jackson 2010). Economists, for instance, would be likely to favor hard, quantitatively oriented methodologies and nomothetic approaches to knowledge (see Becher and Trowler 2001), compared to organization studies scholars on the softer end of the scale. 
Disciplines also constitute "cultures" whose membership involves preferred styles and approaches, shared "experiences and exposures," for example, to particular readings and debates (Wallerstein et al. 2003, p. 453), discourses and positionings (Hyland 2012), and allegiances and identifications (Hyland 2012). Hence, through their disciplinary specializations, students not only internalize ways of knowing-shared cognitive categories, or mental models, through which people perceive and understand the world - they also undergo enculturation into ways of being or cultures with which members of disciplinary in-groups can identify and feel solidarity (Crigger and Godfrey 2014). Taken together, these cognitive and cultural dimensions may be said to constitute prototypes, following social identity theory, which disciplinary in-group members use to represent themselves and distinguish themselves from others.

These dynamics become manifest when neophyte professionals begin to identify themselves as different-sometimes significantly-to people from other professional groups (Trede et al. 2012). As Sarangapani (2011, p. 71) notes, "Socialization into one's disciplinary community involves learning not only about one's own discipline but also about how to view other disciplines." This process can result in divisions that disciplinary members will fiercely defend and which may be so firmly rooted as to constitute "cultural prejudices" (Wallerstein et al. 2003, pp. 456 and 457; Gröschl and Gabaldon 2018; Becher and Trowler 2001). At business schools, for instance, although Management has historically been considered a single profession, distinct disciplinary specializations that instill "strong loyalty" have developed since the 1960s (Khurana 2010, p. 25). Parker (2018, p. 34) observes that 'the business and management curriculum is ... divided into tribes and territories that guard their fields jealously' (Parker 2018, p. 34); Podolny (2009, p. 63 ) bemoans the "balkanization" and "disciplinary silos" of management education; and Gröschl and Gabandon (2018) critique the functional specialization and separation of disciplines that characterize business school curricula and which, they claim, promote dualistic and simplistic thinking among students that impedes them from relating the parts to the whole and thereby from understanding complex phenomena that they will face in their future careers (see also Atwater et al. 2008).

So, while identification with an in-group prototype is known to enable positive dynamics such as empathy and cooperation (Hogg et al. 1995; Ashforth and Mael 1989), as outlined above, it can also manifest as negative attributions vis-à-vis perceived out-groups. It can also disenable individuals' critical scrutiny of their own group attachments (Godwyn 2015; Jenkins 2014; Ashforth and Mael 1989), and override their personal identity through the mechanism of depersonalization, including their notions of "appropriate ways to think, feel, and act" (Hornsey 2008, p. 210). Seen through this lens, an individual's identification with a disciplinary prototype may potentially facilitate a disengagement of their sense of personal responsibility. And by extension, a tightly integrated personal and disciplinary/professional identity may not always be desirable with regard to responsibility (Minnameier 2014). For instance, situations may arise in which individuals must assert their personal responsibility, such as when having to detect, and stand against, malpractice or corruption within their professional organization or in-group, as in the case of whistle-blowing (Robinson 2009); or where they must maintain a critical awareness of blind spots concerning the way in which responsibility is defined and enacted within any given discipline or profession.

The above review shows how individuals are capable of disengaging their own moral standards in the face of contextual factors, using rationalizations that mitigate the negative emotions that might otherwise result from this. Notably, group influences can foster MD, since the powerful appeal of in-group solidarity can result in depersonalization in which individuals subsume their identities to the group prototype. Disciplinary specializations constitute one such form of potentially powerful in-group identification consisting of shared mental models and cultures (often organized along a 'hard-soft' spectrum) and a corresponding out-group 'othering.'

Below, I demonstrate empirically how disciplinary identifications can provide rationalizations for disengaging personal responsibility based on the three mechanisms of moral disengagement outlined earlier: displacement, diffusion, and dehumanization. First, I present the methodology.

\section{Methodology}

The data were collected using focus-group interviews with undergraduate students, conducted within the broader framework of implementation of the UN Principles for Responsible Management Education (PRME) initiative at the Scandinavian Business School (SBS). The SBS is a socalled PRME champion,' that is, a business school that is particularly engaged in contributing to "thought and action leadership on responsible management education."

(UN PRME 2021). At the SBS, complying with this involved implementing a range of initiatives, including gathering data about how staff and students from different disciplinary specializations perceived 'responsibility' issues, and gauging the extent to which responsibility issues were integrated across all undergraduate programs. The primary researchers subsequently offered the author of this article (who was known by them to have a research interest in responsible management education) access to the data with permission to re-analyze it freely. The analysis in this 
article is therefore based on secondary data, since it involves "the further analysis of an existing data set with the aim of addressing a research question distinct from that for which the data set was originally collected and generating novel interpretations and conclusions" (Hewson 2006 in Smith and Smith 2008, p. 3). I will address some ethical implications of this shortly.

Focus-group interviews involve a series of discussions, held in groups of around four to ten people who share features pertinent to the research purpose (here, undergraduate students enrolled in the same year, program and school) (Walden 2012). They are typically used to explore and collect a range of opinions, experiences and knowledge of a topic (Walden 2012) - here responsibility. The resulting, often quite informal, discussions can generate very rich data, as participants elaborate on each other's accounts and sometimes disagree with each other (Wilkinson and Silverman 2004), as is evident in the excerpts presented in this article. They are classified as a qualitative method, and thus offer valuable insights in the field of business ethics, which is generally still dominated by positivist, quantitative approaches (Campbell and Cowton 2015; Brand 2009). However, the interactional nature of focus-group interviews can produce its own challenges. These include domination by, or the silencing/marginalization of, certain participants; a tendency either for extreme views to receive disproportionate attention, or for group members to try to reach consensus at the expense of outlier opinions, such that conformity becomes "an emergent property of the group context" rather than a reflection of individual participants' views (Sim 1998, p. 348; Wilkinson and Silverman 2004; Onwuegbuzie et al. 2009). In the case studied here, in which the focus-group interviews were composed of students from the same disciplinary specialization, and one of the questions explicitly addressed the perception of responsibility within that specialization, there is a risk that responses might have become disproportionately 'we'-/ 'them-us' oriented. Future research could address this by combining focus groups with individual interviews, and/or by mixing participants from different disciplinary backgrounds.

Twenty-four focus-group interviews were conducted, over a five-year period, involving a total of 168 undergraduate business students from a wide range of disciplinary specializations spanning from international business to service management and shipping, as well as business combined variously with philosophy, law, area studies, and mathematics. No pure 'economics' or 'finance' specializations exist at the school in question. However, all undergraduate programs, without exception, include mandatory economics courses and statistics/quantitative methods courses, with the program combining business studies with mathematics being particularly weighted towards the latter type of course. Hence, all students are exposed to the 'hard-soft' distinction, with a greater or lesser emphasis on one or the other. This means that when asked about responsibility in their specializations during the focus-group discussions, they sometimes responded by talking about their specialization as a whole, and sometimes singled out particular courses/subjects. Two to three focus groups were carried out on each program, in years 1,2 , and 3 , where possible. Complete data on all three years are available from nine out of fifteen interdisciplinary study programs representing both 'softer' and 'harder' focuses (see Appendix 2 for a detailed overview of the interviewed programs). Students were recruited on a voluntary basis via their respective study boards, which are a higher education institution in the country in question, composed of a team of elected staff and student representatives from each study program, whose task is to cooperate to administer, develop, and ensure high quality education on that program. They are also the institutional body that reviews research project proposals at the school in question (no independent ethics review board existed at the school at the time the interviews were conducted). The goal when recruiting was to aim for gender parity and internationality wherever possible in the focus groups. Appendix 3 shows the email used to recruit students.

A short, semi-structured focus-group interview guide (see Appendix 1) was designed by the professor in charge of PRME implementation at the school, piloted and then applied by trained staff working with PRME. Students were informed at the start of the interviews that the purpose was to conduct research into the nature and extent of a responsibility dimension in their study program with a view to strengthening this; and that the data gathered would, with their consent, subsequently be presented to their study boards for use in a curricular reform with that purpose. Students were concurrently informed that their contributions would be anonymized. A brief background introducing the UN PRME initiative as a business-school level response to the need to strengthen responsibility learning in the wake of recent financial scandals, was also presented to the participating students at the start of each interview (see Appendix 1). The interview guide consisted of open questions conducive to "expansive answers," flexibility, and authenticity in responses (Lee and Aslam 2018, p. 4; Seale and Silverman 1997). The questions addressed the following topics (see Appendix X): how students would define responsible management education, what did this mean to them in the context of their study program, including whether and how their courses addressed the issue of responsibility; peer and family attitudes to responsible management education; and how students imagined they and their future employers would address this issue. The interviewers deliberately refrained from defining 'responsible management education' or 'responsibility' from the outset, so that the students' own views on this could emerge freely. All interviews were 
conducted in English, transcribed verbatim by research assistants, blinded for confidentiality, and subsequently stored on a secure drive, in compliance with the country in question's Code for Research Integrity (hereafter 'the Code') and the school's General Data Protection Regulation (GDPR) compliance guidelines.

\section{Ethical Considerations}

The reuse of data is permissible under the Code, with the caveat that "Recycling or reuse of primary materials, data, interpretations or results should be clearly disclosed," as has been done here. Data sharing is increasingly recommended, including by major funding bodies, unless there are compelling reasons for protecting it, in order to make optimal use of public funds, and to prevent over-researching of vulnerable populations (Morrow et al. 2014; Grinyer 2009). That notwithstanding, and although qualitative analysis of secondary data is often deemed fairly unproblematic (Morrow et al. 2014), such 'recycling' does raises certain ethical issues that merit discussion.

The first ethical issue pertains to whether or not consent is ongoing and applies to all future uses once the primary data have been collected, or whether consent should be renegotiated every time the data are re-used, possibly at the risk of participant fatigue or irritation (Grinyer 2009). In this case, the students interviewed consented to participate in the primary research, as outlined above, and the primary researchers further observed two key ethical principles recommended by Hammersley and Traianou (2012), namely respecting autonomy (by ensuring voluntary participation and offering participants detailed information concerning the purpose of the research) and protecting privacy (by anonymizing participants). However, the students did not consent specifically to the secondary data analysis that forms the basis for this article, since this was not planned as part of the primary research project - the primary researchers gave the author access to the data set after it was complete. At the time of receiving the data, the author did not have a theoretical agenda at all, except for a general interest in students' views on responsibility. The theme of disciplinary rationalizations for moral disengagement emerged inductively from secondary analysis of the extant data set. However, it should be noted that the focus of the secondary research - the link between responsibility and students' disciplinary specializations - was already explicitly part of the questions asked in the primary research interviews (see focus-group interview protocol in Appendix 1), so the students were aware that this was a point of interest. The secondary researcher (author) sought to further mitigate any potential issues by ensuring the students' anonymity, eliminating all references to the country and school in question, and modifying the names of students' major specializations.
The question of consent in secondary data analysis is complex (Morrow et al. 2014) since the secondary researcher may not have access to the original informants to ask for their consent (Grinyer 2009), as was the case herethe students in question were not identifiable from the transcripts and most had graduated long before the secondary analysis began. Inability to renegotiate consent for secondary analysis is most problematic in cases where the research is sensitive, and where access to, and reanalysis of, the original data could have negative repercussions for participants (Grinyer 2009). In this case, however, the students' identity was protected throughout; and second, they consented, in the primary research, to having their views presented to their own study program faculty - who were arguably those with the most sensitive relationship to them as regards the nature of the data-suggesting that they were not overly concerned about their views being disclosed. Connected to that, Morrow et al. (2014, p. 1) highlight the importance of 'developing and maintaining trusting relationships between primary and secondary researchers' in mitigating potential negative impacts and misinterpretations deriving from lack of contextual knowledge by the secondary researcher-issues of particular important in qualitative research (see also Irwin 2013). In this case, during the secondary data analysis and writing up of this article, the author consulted with the primary researchers on an ongoing basis concerning the context, process and procedure of their research, to ensure that s/he correctly understood these aspects (cf. Irwin 2013). Moreover, the professor in charge of the primary data collection provided feedback on the author's article draft prior to submission, to further check this understanding, and to ensure that students' anonymity was protected and that their views were correctly represented.

\section{Data Analysis}

Acknowledging that disciplines consist not of only knowledge structures, but are also social constructions about which people tell 'stories' (Young 2008; Becher and Trowler 2001), the analysis was carried out from a social constructivist perspective, emphasizing how individuals construct shared meanings (or not) around the topic of disciplines and responsibility. However, in this case, the objective was not to probe each individual respondent's unique perceptions and motivations (Stewart and Shamdasani 1990; Walden 2012; Krueger and Casey 2014), as the group, not the individual participants, constituted the unit of analysis, as is often the case with focus-group data analysis (Morgan 1997). The goal was to identify "big ideas" arising from "an accumulation of evidence ....rather than from isolated comments" (Krueger 1998, p. 38). In this case, open questions posed in the focus-group interviews generated rich qualitative material for thematic identification and analysis, which was used to 
construct the theoretical framework presented in this article, which can later be tested using more "conventional," quantitative approaches such as a survey (Weaver and Treviño 2015, p. 4; Smith and Smith 2008). The interview transcripts were inductively analyzed by the author using qualitative content analysis, which aims to describe the meaning of qualitative data by reducing it to concepts based on detailed and self-critical readings of the data set (Schreier 2012; Elo et al. 2014). The author consulted the audio recordings in cases where she was not sure of the meaning. Using Nvivo 11 software, first-order codes-or "nodes"-were identified in the data, and interview excerpts were assigned to them, resulting in a coding frame. Codes were added and refined on an ongoing basis, in order to achieve more precise or encompassing categories, and categories that seemed to duplicate each other were merged.

This initial coding produced several major themes, one of which was the "link between disciplines and sense of personal responsibility" theme discussed in this article. The first-order concepts pertaining to that theme were then re-analyzed as a separate body of data, producing secondorder themes, which were then abstracted into three aggregate dimensions that describe the research phenomenon (cf. Gioia et al. 2013), here the implications of students' rationalizations about disciplinary specializations for their sense of personal responsibility. These three dimensions are: (i) mental models, that is, students' cognitive representations of disciplines; (ii) disciplinary culture, expressed as in- and out-group-based prototypes and responsibility attributions; and (iii) moral autonomy, expressing a belief in individual moral sovereignty and simultaneously others' (but not one's own) moral fallibility. Given that the coding process can be intuitive and hard to explain (Schreier 2012), a model is provided in Fig. 1 following Gioia et al. (2013), offering a "chain of evidence" showing how these three themes were derived from the data (Brinkmann 2013, p. 113; Elo et al. 2014).

Within each of these three dimensions, the data showed that students used various rationalizations to either claim responsibility for their discipline, and/or to deflect it, both ways resulting in the minimization of personal agency with regard to responsibility. The relationship between the three overall dimensions, and the rationalizations deployed within each, is summarized in Table 1. I then began an iterative process of cycling between data and theory (cf. Orton 1997), searching for concepts that could clarify the responsibility dynamics identified in the data. Here, social identity theory was helpful in accounting for the disciplinary in-group based rationalizations mobilized by the students, as well as the shift from individual-level to group-level responsibility attributions through the mechanism of depersonalization. Moral disengagement theory captured the different types of disengagement strategy mobilized in these rationalizations. Based on this, the conceptual framework was then constructed.

The study has several limitations. First, the author was not able to ensure a complete data set, or to influence the study programs chosen for the interviews, the interview questions, and set-up. For instance, only one of the interview questions pertained directly to responsibility and disciplinarity. Further research should develop a research design that sets out to compare students' views on the link between responsibility and disciplinarity across a range of harder and softer, pure and applied, and mono- and interdisciplinary specializations, as well as specifically investigating the relationship between disciplinary and personal responsibility. Second, the study was carried out at a single business school; hence, the findings may not be generalizable to other business schools. That said, given the status of the SBS as a PRME champion, it ought to represent one of the most progressive schools in terms of working towards students' overall responsibility awareness. Also, consistent with the exploratory intent of the research, my aim was to generate a theoretical framework amenable to subsequent testing and not to generalize empirically based on the findings (cf. Stebbins 2001). Third, information on the student focus-group participants was limited to their study program and year; systematic data on other demographics were not available; hence, it was not possible to make meaningful connections between, for instance, gender/cultural background and students' perceptions of responsibility with regard to their disciplinary specializations, something that future research should address. Finally, taking the group as the unit of analysis and analyzing emergent themes, as is often done with focus groups and as was the case here, may not provide an accurate picture of dissent or outliers within the group (Onwuegbuzie et al. 2009). Related to this, dissenters who may have chosen to remain silent were not represented in the transcript. Future research might address these issues, thereby enhancing validity, by coding specifically for silent participants, outlier views and 'argumentative' or negative interactions; conducting followup individual interviews with less vocal participants; and/ or conducting 'verification' focus groups to test the themes that emerge during the original focus groups, as suggested by Onwuegbuzie et al. (2009).

\section{Findings}

Below, I present findings showing how the disciplinary context, expressed through disciplinary prototypes consisting of mental models and disciplinary cultures, shaped students' rationalizations about responsibility. I identify three rationalizations mobilized by students either to claim responsibility for their discipline or to deflect 


\section{First-order codes (examples)}

\begin{tabular}{|c|}
\hline 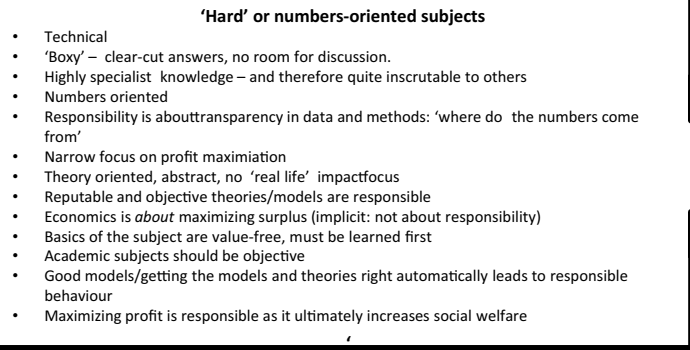 \\
\hline $\begin{array}{l}\text { 'Soft' or discussion-oriented subjects } \\
\text { Cultural sensitivity } \\
\text { Critical thinking approach } \\
\text { Complex, no clear-cut answers } \\
\text { Less likely to find a job } \\
\text { Reflexive } \\
\text { Provide insightinto different points of view, giving a better basis for decision-making } \\
\text { Focus on the 'bigger picture' (employees, welfare, society, environment), not 'just business' } \\
\text { Thinking for oneself, developing own opinion, not just rote learning } \\
\text { Real- life examples and experience-sharing, not just theory } \\
\text { Balance between profit and caring / responsibility } \\
\text { Social, human approach, not 'cold' } \\
\text { Focus beyond narrow profit maximization }\end{array}$ \\
\hline 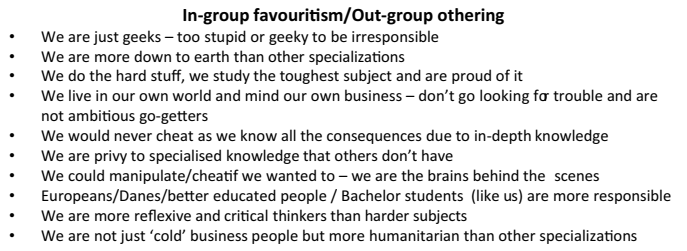 \\
\hline $\begin{array}{l}\quad \text { Personal choice / inclination to be responsible } \\
\text { Upbringing shapes sense of responsibility } \\
\text { Responsibility is 'common sense' } \\
\text { 'Reasonable people' are responsible } \\
\text { Responsibility can't be taught, it's just human nature (or not) } \\
\text { People know the difference between right and wrong - they don't need to be taughtit } \\
\text { People who wantto cheat will do it regardless (e.g. of studies) } \\
\text { Values are set long before students reach business school, so theycan't be changed } \\
\text { Situation can sometimes influence decision to be responsible or not }\end{array}$ \\
\hline
\end{tabular}

Second Order Codes

\section{Aggregate Themes}

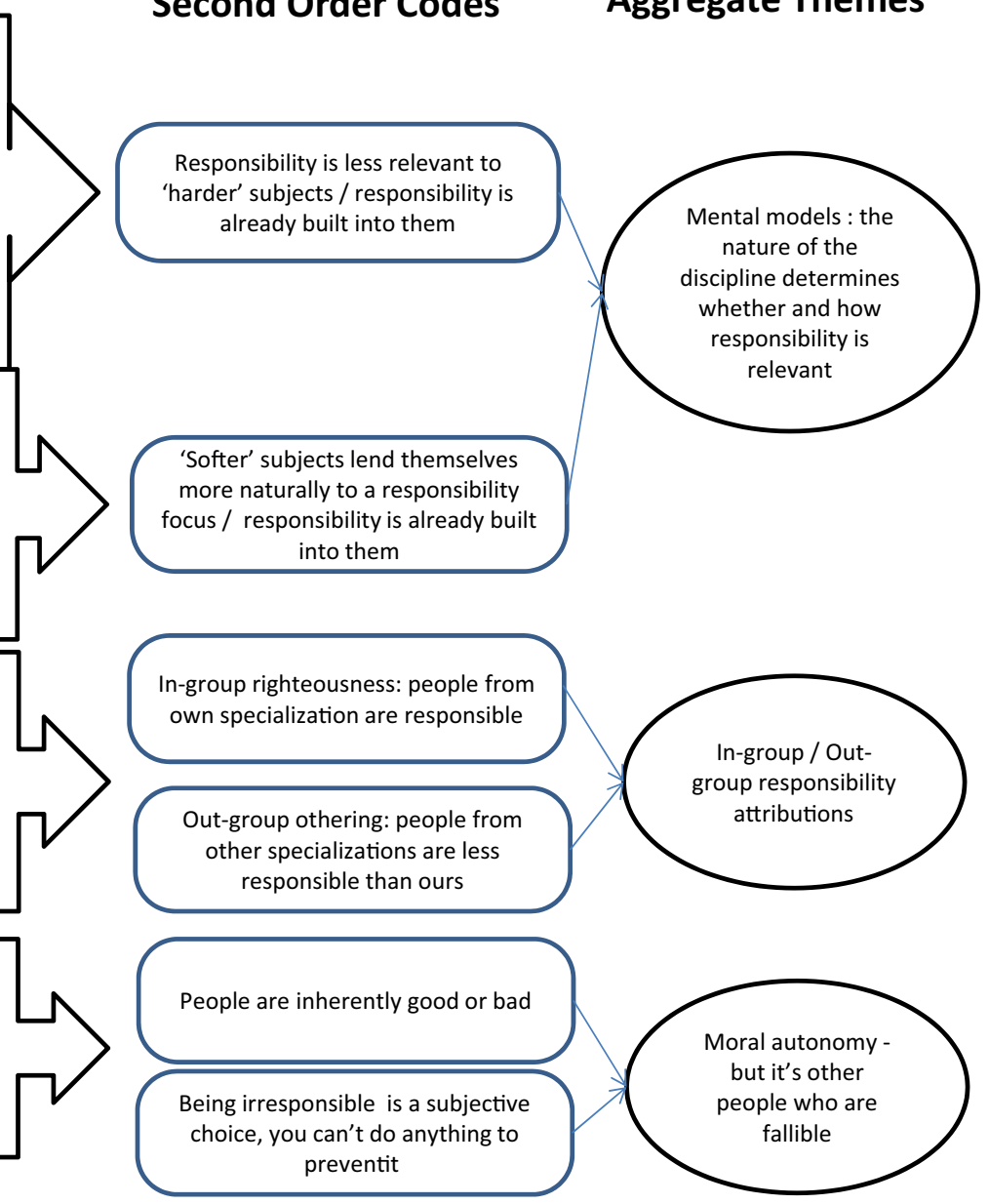

Fig. 1 Coding Chart

responsibility from it: (i) "responsibility is not relevant to the discipline/specialization"; (ii) "responsibility is already embedded in our discipline"; and (iii) "our specialization is more responsible than X specialization." I then discuss a fourth, cross-cutting rationalization, namely students' concurrent belief that responsibility was a matter of individual moral agency, with 'bad apples' largely blamed for irresponsible behavior. Table 1 outlines how these rationalizations relate to mental models and disciplinary cultures in hard vs soft disciplines, as well as to the three mechanisms of moral disengagement described earlier, and summarizes the implications for personal responsibility.

\section{Mental Models}

Students defined 'responsibility' quite differently depending on their mental models of their specializations.
However, two main rationalizations were used to deflect and claim responsibility for their discipline, respectively: (1) that responsibility was 'not relevant' to the discipline/ specialization and (2) that responsibility was embedded in it.

\section{“Responsibility Is not Relevant"}

The first rationalization, which pertained to harder specializations and disciplines, was that these were "not about right and wrong" since they were essentially "objective," "technical," "theoretical," or "basic." Students on the most numbers-oriented specialization at the SBS, Business, and Mathematics, were particularly insistent on this (see excerpts in Supplementary Box 1). They portrayed their specialization as "boxy," oriented towards calculation, numbers and facts, and therefore as not requiring a responsibility focus. These students defined their task 
Table 1 Disciplinary-based rationalizations for moral disengagement

Type of discipline Mental models / Disciplinary identifications

'Harder' specializations Mental models

Disciplinary culture

In-group/out-group responsibility attributions

Disciplinary culture
A priori MD mechanism

DIFFUSION (division of labor)

Rationalization: Responsibility is not directly relevant to this specialization because it is neutral/technical/basic/ objective in nature

Onus for responsibility: Personal responsibility shifted away from own specialization (and thereby away from oneself)

Student concludes: It's not the job of people working with this discipline/ specialization to take care of responsibility issues

DISPLACEMENT (minimizing own agency)

Rationalization: Responsibility is a priori 'built into' my specialization

Onus for responsibility: Personal responsibility shifted onto own specialization's models and theories (and thereby away from oneself)

Student concludes: I don't need to worry about responsibility. The models / theories in my own specialization will take care of that

DISPLACEMENT (minimizing own agency)

Rationalization: My in-group is naturally responsible in its own technical/geeky/knowledgeable way

Onus for responsibility: Personal responsibility shifted away from own in-group (and thereby away from oneself) Student concludes: My specialization's in-group is inherently responsible in its own way so no need for me to worry about that

DEHUMANIZATION (casting others as bad people) Rationalization: People from other specializations are ambitious, greedy, less knowledgeable

Onus for irresponsibility: Personal responsibility shifted onto out-group/s (away from own in-group and thereby indirectly away from oneself)

Student concludes: Other specializations are less responsible than ours (in-group self-righteousness)

DISPLACEMENT (minimizing own agency)

Rationalization: Responsibility is embedded in our specialization as, e.g., critical thinking/cultural sensitivity

Onus for responsibility: Personal responsibility shifted onto own specialization's approaches (and thereby away from the individual)

Student concludes: My specialization's in-group is inherently responsible in its own way so no need for me to worry about that

DISPLACEMENT (minimizing own agency)

Rationalization: We are reflexive, critical, humanitarian, 'big picture' people

Onus for responsibility: Personal responsibility shifted away from own in-group (thereby away from oneself)

Student concludes: My specialization's in-group is inherently responsible in its own way so no need for me to worry about that

DEHUMANIZATION (casting others as bad people)

Rationalization: Other specializations are unreflexive, cold and profit-oriented, uncritical, don't see the bigger picture Onus for irresponsibility: Personal responsibility shifted onto out-group/s (away from own in-group and thereby away from oneself)

Student concludes: Other specializations are less responsible than we are (in-group self-righteousness) 
Table 1 (continued)

\begin{tabular}{ll}
\hline Type of discipline & Mental models / Disciplinary identifications A priori MD mechanism \\
\hline Across specializations & DEHUMANIZATION (casting others as bad people) \\
& $\begin{array}{l}\text { Rationalization: Responsibility is a matter of individual moral agency_but (other) people are fallible } \\
\text { Onus for responsibility: Personal responsibility shifted onto 'bad apples' } \\
\text { Student concludes: You can't do anything to prevent irresponsible behavior_bad apples' will be bad whatever you } \\
\text { do-but in any case it's not me who's the problem }\end{array}$ \\
\hline
\end{tabular}

as being "the brains behind the scenes," crunching numbers, helping to maximize profit, and producing 'objective facts' that other people, such as managers, had to apply in the real world. As one 3rd-year Business and Mathematics major expressed it, "We don't think about leadership, about being leaders. We think about being given a task and performing that task and not being responsible for the background stuff."

Since such disciplines were regarded as 'objective,' misusing their knowledge was seen as a subjective choice and not something that needed to be taught: "it is like when you learn to use a hammer you are not told not to hit someone in the head because it will hurt him. It's like that in our program. Now you have the knowledge. 'Don't do this and don't do that' - I think it is irrelevant" (2nd-year Business and Mathematics major, see also Supplementary Box 1, Excerpts 1 and 2). Students from another harder specialization, Business Administration (Supplementary Box 2, Excerpt 1), voiced a similar idea that harder subjects like Finance and Microeconomics were 'basic' or 'fundamental,' and therefore exempt from responsibility considerations-they just had to be learned 'as is,' before their 'real-life' application could be taken into account.

Even some students majoring in softer specializations asserted that responsibility had little place in subjects like macroeconomics where "of course we are not going to learn about ethics" (Area Studies major), or managerial economics, where "you are not going to talk about impact on the society, but first of all it is about maximizing shareholder and that sort of stuff' (Business and Politics major). Business and Politics majors largely referred to responsibility as a 'detail,' 'in-depth' issue and therefore not compatible with 'basic' micro/macroeconomics courses or even with 'basic political science' which was about 'getting the institutions and systems right.' Softer disciplines were, conversely, regarded as the more natural terrain of responsibility. As one Area Studies major put it: “... it's also easier when you have soft subjects, because it's difficult in microeconomics or business research methods. Like, I don't really see how it fits in as well as in the other subjects". Softer disciplines were described as more compatible with caring about society, culture, 'welfare, 'the human side' and the environment, and as people- not just profit-oriented. Several students from harder specializations openly viewed responsibility as a teaching topic with disinterest or cynicism. For instance,
Business Administration students across all three cohorts spoke of boredom, falling asleep, and "watch[ing] paint dry," of corporate social responsibility (CSR) as "bullshit" so companies can look good and "to create jobs for professors," of "drowning in theories," as being "obvious" and something that didn't need to be taught as everyone already knew it, and as "something that we need to do so we can get back to the numbers-back to the fun part." One 2nd-year Business Administration major remarked that: "one funny note here is the joke I thought was most fun in all of SBS. I remember our [specialization's] Tumblr profile. There was this gif that said: 'corporate social responsibility,' and then a little girl going towards the window and tossing money out of it. I was just like... That was meant as a joke, but that is pretty much the feeling that we have."

Not all students agreed with this cynical take on responsibility, however. For instance, a Business and Politics major asserted that responsibility was an important part of learning the "basics" (Supplementary Box 3, Excerpt 1); and a 3rdyear Business Administration major pointed out that responsibility should be addressed in classes when relevant: "and not just you know; "now we have one session about CSR and let us go to the real finance thing after that'." And this 2nd-year Business Administration student felt that "we need more discussion in our specialization. It's very facts and profit-maximizing oriented. I think it would be good for us to learn more about it [responsibility]. This may reflect the fact that not all students identify to the same extent with the way a discipline/specialization is constructed by their teachers or peers, and/or do not necessarily agree with the way it is taught.

However, in general, these students' views on responsibility reflected a dominant economic logic that marginalizes social and political dimensions (Antonacopoulou 2010, p. 10; Ghoshal 2005), as well as what some have termed an epistemological bias at business schools towards "simplified knowledge" (Ehrensal 2001, p. 104). This bias is mirrored in the business world where "financial and market strategists who have been conditioned to respect only 'hard' and quantifiable "facts" find it easy to dismiss human issues as "'soft' or 'mushy" since they have no " hard' data to support them" (Cartwright and Cooper 1995, p. 35). The 'responsibility is not relevant' rationalization was also generally aligned with Biglan's classification, whereby hard disciplines favor unambiguous results and shun 'real-world' 
application, making complex, contextually contingent moral issues extraneous, thereby exempting them from directly addressing responsibility. This rationalization recalls the so-called separation thesis that business decisions have no moral content and moral decisions have no business content (Harris and Freeman 2008; Wicks 1996). This idea that facts can be separated from values is, according to some scholars, "ingrained in all that we do in business schools," and leads to the notion that business theories can be morally neutral "while surreptitiously encapsulating certain ethical values and assertions" (Harris and Freeman 2008, p. 543; Ghoshal 2005). This rationalization also reflects Bandura's diffusion strategy, that is, a division of labor whereby the nature of a specific task/job (or here, discipline) obviates moral considerations. Using this rationalization, blame for irresponsibility can potentially be shifted from the innocuous discipline and its practitioners, to 'bad apples' who might misuse its tools. Following the concept of depersonalization (cf. SIT), this rationalization further potentially exempts those identifying with the disciplinary in-group in question from assuming responsibility since that is 'not their job.'

\section{"Responsibility Is Embedded in our Specialization"}

Interestingly, although some students were reluctant to acknowledge responsibility as directly relevant to their specialization, they nonetheless espoused quite specializationspecific responsibility codexes. For instance, Maths students professed a firm belief in objectivity, and the integrity of their specialization's models and theories (Supplementary Box 1, Excerpt 1) as well as transparency about methods and data; Business Administration students saw responsibility in terms of optimizing profit within the limits of the law and ethical standards, making decisions based on finance, being able to shut off 'irrelevant' matters, and as a means to improve profits and marketing for one's company, and considering longer-term, social considerations not just "quick fixes"; Shipping majors emphasized environmental responsibility and thinking of the consequences of one's decisions for the future and for geographically distant contexts; and for Business and Service Management students, responsibility was about control, overview, and loyalty, knowledge-sharing and understanding the customer.

This brings us to the second rationalization, which was expressed both by students from harder and softer disciplines, namely the notion that responsibility was a priori built into a discipline/specialization's models, theories and approaches, and that being responsible was therefore basically a matter of mastering one's professional toolbox. For instance, Maths majors felt that they had 'indirect responsibility' as long as they "us[ed] the models right" (Supplementary Box 1,
Excerpt 1) - and that beyond this, there was no need to discuss responsibility explicitly. If those models/theories were endorsed or used by external authorities, then that further obviated any need to concern oneself with responsibility (Supplementary Box 1, Excerpt 1). Mastering these basic tools was also seen as equipping them to detect irresponsibility. As one Business Administration major put it: "we would be good at detecting anything irresponsible if it was going on, because we know something about finance, accounting and we know many things, so maybe it will be easier for us to spot if something wrong is going on".

A related idea emerged in mental models of students from softer specializations, who depicted responsibility as mostly implicitly embedded in their studies, manifesting through a particular thematic emphasis that functioned as a proxy for it. For instance, Business and Philosophy majors espoused a view of responsibility as not about being directly told what was right and wrong, but involving a critical approach and not "just accepting" what you are told (Supplementary Box 6, Excerpt 1). Data Management majors talked of "openness" as a better descriptor for their specialization than responsibility per se (Supplementary Box 4, Excerpt 1).

And Area Studies majors interpreted responsibility as "integrated," "embedded," and "not outspoken" in their specialization, where it manifested as a focus on cultural awareness and critical thinking, as well as a more "reallife," practical perspective (Supplementary Box 5, Excerpt). They felt confident, too, that they could transfer this critical mind-set from their softer subjects to their harder ones, making them responsible in those arenas as well.

The caginess about responsibility expressed by some students may, thus, in some cases be more an objection to addressing this explicitly and/or to broadening the remit of how they define responsibility in relation to their disciplines, than a rejection of responsibility per se. This ambiguity is evident in this comment by a 3rd-year Business Administration student, who, immediately after claiming that learning about responsibility at SBS was "bullshit," continued: "It is not that we don't feel responsible but it is just the term. People try to categorize it in certain boxes I think that is what offends me at least."

That notwithstanding, following this rationalization, responsibility can potentially either be displaced onto the discipline (seen as a 'naturally responsible' authority) and its often quite narrowly constructed remit, or onto an external, legitimizing authority endorsing the discipline's approaches, in both cases exempting students from addressing it explicitly.

\section{Disciplinary Cultures}

The third rationalization, "our specialization is more responsible than X specialization" reflected in-group and 
out-group dynamics, which manifested in the way that students from several specializations leveraged their specialization's prototype to claim that they were more responsible than other specializations.

\section{“Our Specialization Is More Responsible than X Specialization"}

Business and Maths majors, for instance, constructed their disciplinary in-group as more responsible than other specializations (dehumanization) whom they considered too ambitious, competitive, and 'fancy,' reflecting the interplay between identity and alterity outlined earlier (Supplementary Box 1, Excerpt 4). They described themselves as guileless geeks who would never behave irresponsibly (Supplementary Box 1, Excerpts 3 and 4). These students' repeated use of the term 'we' shows their identification with perceived prototypical characteristics of their own specialization's in-group (depersonalization cf. social identity theory), namely shared mental models (boxiness, structured, numbers-oriented); and shared traits/attitudes (kind, helpful, down-to-earth, non-competitive/ambitious), self-presentations (casual dress form), and pride in being a 'tough' specialization. Using these perceived characteristics to construct their specialization's in-group (and thereby themselves as in-group members) as naturally responsible compared to others, the need for personal agency with regard to responsibility issues is minimized (displacement).

Students from some softer disciplines similarly compared themselves favorably to disciplinary out-groups with regard to responsibility. For instance, Philosophy majors compared their in-group prototype as critical thinkers to Business Administration majors ('Flemings'), whom they regarded as uncritically accepting what they were taught (Supplementary Box 6, Excerpt 1). And students majoring in Area Studies felt that their critical focus gave them a responsible mind-set compared with 'hard-core economists' (Supplementary Box 5, Excerpt 1), and saw themselves as more independent thinkers than those taking "hard" subjects, whom they depicted as uncritically engaging in rote learning (Supplementary Box 5, Excerpt 4). For their part, Business and Politics majors depicted their in-group as more caring and less profit-oriented than their (academically very close) peers studying pure International Business, whom, they asserted, would just "laugh in your face" (2nd-year Business and Politics major) if you talked to them about responsibility (see also Supplementary Box 3, Excerpts 2 and 3). Here, the student suggests that their own specialization attracted people with a naturally "caring" identity in the first place (displacement), rather than this being fostered by the learning context-yet still leverages the disciplinary prototype as a way to claim righteousness for his/her own in-group compared to the International Business out-group (dehumanization).

Thus, what are, ostensibly, positive in-group traits with regard to responsibility, like critical thinking, are here mobilized to disadvantageously compare with outgroups and claim moral superiority for the disciplinary in-group. The tendency to regard one's own specialization as superior-here more responsible-than others, based on 'binary oppositions' (such as 'down-to-earth' versus overly-ambitious) or other 'stereotyped characteristics [that] stand in for individuality' (depersonalization cf. SIT) is widespread and has, in some cases, been found to persist post-university (Warering 2009, p. 924). This 'ideological work' identifies (positive) coherence within the disciplinary in-group and simultaneously takes a reductive view of out-groups as homogeneous, enabling blanket negative characteristics to be attributed to them (Warering 2009, p. 924). Some students seem to think that these in-group characteristics derive from the disciplinary context, while others described them as personality traits that attracted certain types to particular disciplines in the first place. But either way, perceptions of a responsible ingroup compared to an irresponsible out-group potentially enable displacement of irresponsibility away from the ingroup, and onto the out-group through dehumanization, thereby indirectly exonerating in-group members.

Summing up on first three rationalizations: students drew on disciplinary prototypes to define what it meant to be responsible (or not), with the hard-soft distinction playing a key role in how they rationalized about this-for instance geekish, critical, holistically oriented. And although each specialization defined responsibility differently, the three moral disengagement strategies of diffusion, displacement, and dehumanization were evident in the rationalizations students across specializations used to minimize the relevance of responsibility to certain disciplines/specializations, to claim responsibility for their own disciplines, and to deflect irresponsibility onto out-groups from other specializations, thus exempting their own specialization (and thereby indirectly themselves) from this. The disciplinary context thus becomes an important factor for how students define and delimit their own responsibility, that of their specialization, and that of other specializations. These rationalizations reflect similar logics that have been found to erode the moral climate in firms and other organizations, notably silo thinking (Serratt 2017), a narrow focus on specific tasks, and the shifting of personal responsibility onto institutional representatives, as witnessed in recent financial crises and corporate scandals (Robinson 2009; Bansal and Kandola 2003; Sims and Brinkmann 2003). 


\section{Bad Apples}

Despite invoking the disciplinary context in different ways in order to claim and/or deflect responsibility, many students simultaneously held that responsibility was a matter of personal choice and common sense, and that irresponsibility was the domain of intrinsically flawed (other) individuals, reflecting the MD mechanism of dehumanization. For instance, 3rd year Maths majors described irresponsible behaviors as resulting from a personal inclination to misuse knowledge, making (others') subjectivity the fallible point with regard to (ir)responsibility, and not their own discipline or the way it was taught (Supplementary Box 1, Excerpt 1). Business and Politics students debated whether several years of study would make any difference if a person were inherently bad (Supplementary Box 3, Excerpts 2 and 3), with one student perceiving that students from a rival specialization or those who were simply 'ruthless' would be impervious to the school's attempts to foster more socially oriented attitudes (Excerpt 3). Other students asserted that individuals' sense of responsibility was determined long before they reached business school (see Supplementary Box 2, Excerpt 3); that although people could sometimes change, "your values and your integrity are from your parents and your society"; and that the way responsibility was taught would make no difference since 'people who are bad people will be like that either way.' Ultimately, even though some students appreciated that the "new perspectives" their studies gave them could help them to ascertain whether something was right or wrong, and gave them "tools to address the problem," most were skeptical that this knowledge would change anyone's decisions. People, they felt, knew instinctively what was right and wrong and trying to change their morals was "pretty hard": "we know that you should take into account responsibility"; "we assume everyone should know about it"; and "if you want to cheat, you will find a way"-_if your mind is screwed."

This 'bad apple' notion potentially undermines students' sense of personal responsibility since it allows unethical behavior to be "blamed on a few individuals with poor character" (Treviño and Nelson 2016, p. 13). It also shows that students do not seem to consciously acknowledge the potential effect of their disciplinary context on their own moral reasoning, and of the fact that people (including themselves) are more likely to comply with the standards in their context than to critically evaluate and challenge them (Godwyn 2015; Bandura 1999). With some exceptions, few seemed aware that one does not have to be a 'bad apple' to behave like one in certain situations, reflecting a Western tendency to "honor a state of individual, 'subjective' agency"- the notion that one can rationally deliberate about, and control, one's actions independently of social context (Mcnamee and
Gergen 1999a, b, p. 6). The students' rationalizations also suggest that they believe they have themselves attained a post-conventional level of moral reasoning and moral autonomy, as per Kohlberg's (1969) model outlined earlier. These findings resonate with other research showing that individuals are not always aware that their ethical stance may be contingent on external factors, and typically underestimate their impact (Godwyn 2015, p. v; Baker 2014; Card 2005). For instance, Godwyn's (2015) cross-national study of ethics among business students showed that although the students' ethical positions shifted depending on the group they were currently identifying with, the students did not seem aware of this inconsistency. And Schlenker et al. (2009) note that US college students 'regard themselves as more principled than the typical person and believe they behave consistently with their principles most of the time,' despite increasing evidence of cheating and unethical behavior.

\section{Summary of Findings}

The findings show that students defined responsibility in discipline/specialization-specific ways, which also enabled them to deploy various rationalizations either to claim responsibility or deflect it. Table 1 outlines how these rationalizations relate to mental models and disciplinary cultures in hard vs soft disciplines, as well as to the three mechanisms of moral disengagement described earlier, and summarizes the implications for personal responsibility. First, many students regarded responsibility as less relevant to harder disciplines than to softer ones, and therefore typically 'not the job' of those disciplines (diffusion); or as a priori taken care of by, or integrated into, those disciplines' basic models, theories and approaches (displacement), thus obviating the need to address responsibility directly themselves. Second, students from several specializations regarded their in-group as more responsible than out-groups from other specializations (dehumanization). Third, despite the fact that students drew extensively on the disciplinary context to define what constituted their responsibility and what did not, many nonetheless simultaneously seemed to regard responsibility as a context-independent personal matter. Or, they regarded values as defined by other contextual factors, such as parents or society, that were established long prior to admission to business school and unlikely to be affected by the educational context. Further, they perceived irresponsibility as something that people from other specializations or dysfunctional people (bad apples) were more prone to (dehumanization). Missing from most students' accounts was a critical appraisal of their personal fallibility, and that of their disciplinary specialization and its in-group, with regard to the potential for irresponsibility. 


\section{Discussion}

Business schools have a duty to educate 'ethically responsible professionals who will positively contribute to the ethical environment of business' (Klein et al. 2007, p. 198). They are also key agents of 'secondary socialization' of business professionals, and there is evidence that students' attitudes, values and behaviors in relation to responsibility are shaped significantly during their business school years (Lämsä et al. 2008, p. 46-47). Higher education, more broadly, is also known to be a major moment in students' lives in which they 'question and redefine their core sense of who they are' Colby and Sullivan (2009, p. 24). We therefore need a robust understanding of how different aspects of the business school context and experience influence how students think about responsibility (Baker et al. 2006).

Research on strengthening business students' moral reasoning and sense of responsibility has so far largely aimed at strengthening the individual student's personal values and/ or his or her knowledge about responsibility and ethics, inter alia (Cooper et al. 2005; Treviño and Nelson 1999), independently of 'the surrounding context of values, personal relationships, or community influences' that also play in (McNamee and Gergen 1999a, b, p. 8; Gu and Neesham 2014; Cunliffe and Eriksen 2011, p. 1430). Several scholars have therefore recommended that business schools pay attention to how these (often implicit) aspects of the learning context impact responsibility learning (Parker 2018; Blasco 2012 and 2020; Solitander et al. 2012; Ehrensal 2001; Treviño and McCabe 1994), and engage in a reflexive process which questions that context, including its 'underlying normative values and assumptions ... which ultimately determine its ethical standards' (Floyd et al. 2013, p. 758; Solitander et al. 2012; Treviño and McCabe 1994). Such reflexivity is not something that business schools generally excel at, however (Solitander et al. 2012; Antonacopoulou 2010).

This article seeks to contribute to that reflexive endeavor by showing how students' disciplinary specializations constitute an important but overlooked element of the business school responsibility learning context. As outlined earlier, identification with disciplinary specializations is generally thought to strengthen individuals' sense of responsibility by fostering their awareness of professional codes and standards and ensuring that their personal values and behavior are consistent with these (Crigger and Godfrey 2014). However, as shown above, such identification can also provide rationalizations that potentially enable students to disengage their sense of responsibility. The theoretical framework presented in Fig. 2 combines two theories to explain how this works. SIT theory accounts for how disciplinary specializations constitute in-groups featuring perceived prototypical features with which students may identify, and which define how they think about what constitutes (or not) their responsibility. These identifications may override their personal

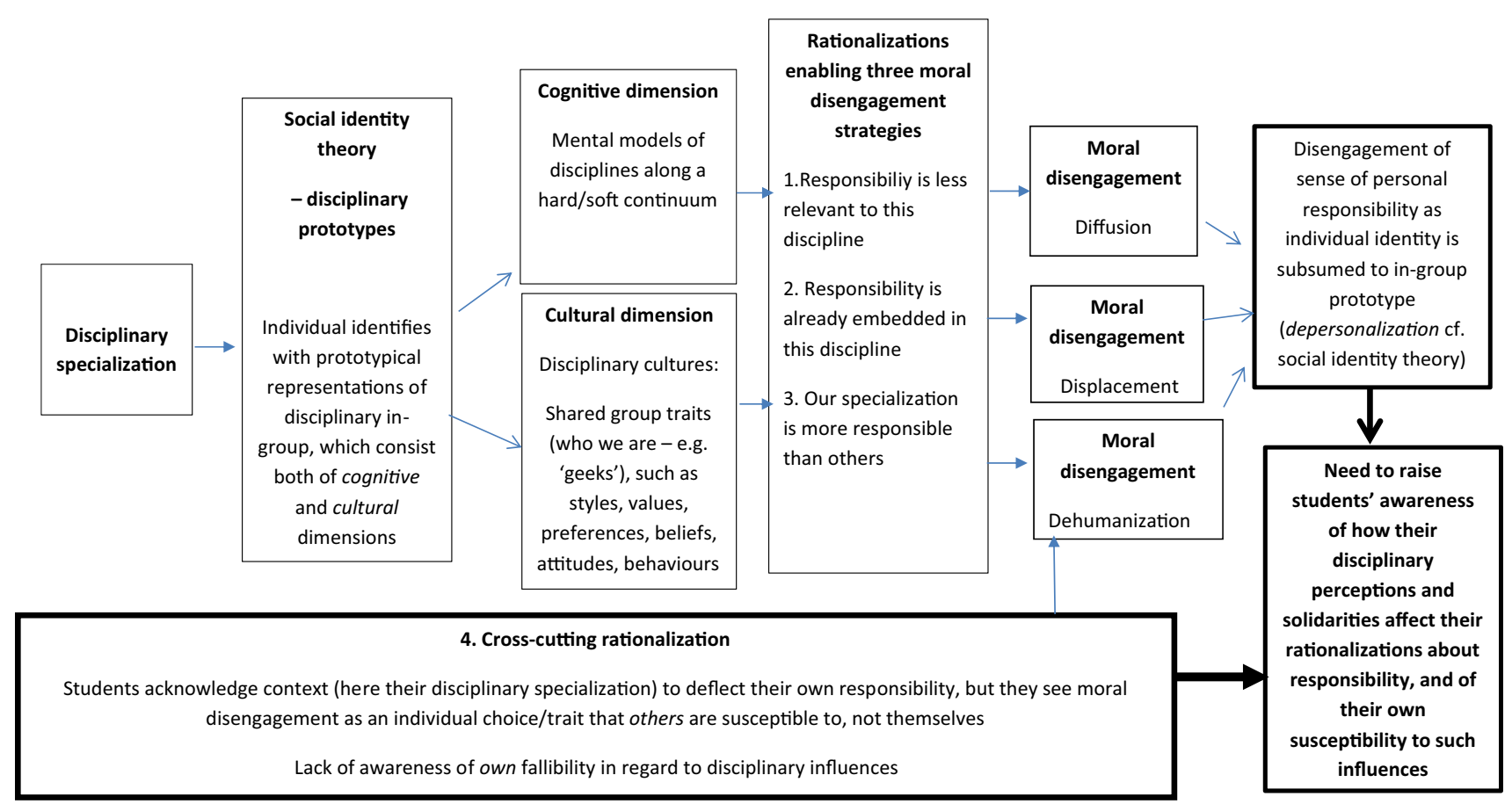

Fig. 2 Conceptual framework 
identities through the mechanism of depersonalization (Hornsey 2008), opening up for a shift in focus from individual to in-group-level responsibility and a corresponding loss of 'ownership' over their thoughts, beliefs and actions and over their sense of responsibility for these (Hiemstra and Brockett 1994). That shift is underpinned by rationalizations that variously reflect the three moral disengagement strategies described earlier (see Table 1). In this way, the theoretical framework accounts for how the disciplinary context can offer justifications for the disengagement of personal responsibility. At the same time, many students seemed unaware of their own susceptibility to this contextual factor, asserting instead a belief in their own moral autonomy (cross-cutting rationalization).

This is not to say that the rationalizations outlined in the theoretical model will necessarily lead to moral disengagement in concrete situations; that all students identify to the same extent with their disciplinary specializations, or that they all use these rationalizations. Clearly, not all students agreed about the role that responsibility played, or should play, with regard to their disciplinary specializations. Disciplinary socialization is an ongoing process and students may accept, or resist, the "moral order" of a discipline-its "basic beliefs, values, norms and aspirations" (Ylijoki 2000, p. 341 ) - to different degrees. Their orientations towards their disciplines may also be influenced by the way they are taught (Gresalfi and Cob 2006). Furthermore, it is not surprising that students describe responsibility in discipline-specific ways-many of which are highly commendable-when asked to do so. However, the point here is, rather, to show how the disciplinary context offers a repertoire of justifications for morally disengaging that can potentially be drawn upon when "expedient" (Schlenker et al. 2009, p. 317) or when the context supports this. As Bandura's work shows, people rely on exactly such justifications to selectively disengage their own moral standards without self-recrimination.

Why do students' rationalizations about responsibility in relation to their disciplines matter? First, because as research on cognitive moral development has shown, moral judgements are connected to moral action: in other words, "how people think is related to what they do" (Treviño 1992, p. 446). Related to this, moral disengagement is a predictor of future unethical behavior (Detert et al. 2008). Therefore, as Rajeev (2011, p. 59) remarks, it is important to examine 'elements ... that may act as antecedents of MD' and which affect people's ethical choices-here students' rationalizations about responsibility in relation to their professional disciplinary specializations that may offer justifications for MD in their future working lives. Second, because there is no code of professional conduct for management per se (Escudero et al. 2015, p. 9), moral decisions in organizationswhere most students will work after graduation-are often ultimately left to individuals, particularly when it comes to gray areas not explicitly covered by a specific organization's code of conduct (Gibson 2000). This makes it all the more important that individuals are aware of their own moral susceptibility to contextual factors. As Minnameier (2014, p. 57) points out, 'autonomy and responsibility have become key elements in the modern organization of work, and with more autonomy of the personnel the moral responsibility also increases.' That is no guarantee of responsible conduct, however, as evidenced by the well-documented tendency towards "moral buck-passing" in organizations-that is, the attempt to avoid blame by using rationalizations such as blaming others, claiming obedience to authority, or stating that "it's not my job," with a view to keeping one's selfimage unsullied (Bivins 2006, p. 31). These rationalizations resemble those used by some students in this study, namely the belief that responsibility is simply not part of the "natural' terrain of some disciplines; taking presumed authoritative models and theories in good faith; and a tendency to assume that irresponsible actions are generally committed by others such as disciplinary out-groups or individual 'bad apples.'

This is not to suggest that students will necessarily replicate their disciplinary identifications from school in the world of work when it comes to rationalizing about responsibility. However, some scholars have suggested a link between past and future MD (Fida et al. 2018), suggesting that the disciplinary-based MD mechanisms addressed here may endure in students' professional lives after business school. And, as literature on organizational silos shows (Serratt 2017), the propensity to think in terms of professional categories and in- and out-groups does appear to persist when it comes to working life after graduation. Seen from that perspective, it is not disciplines (or their corresponding professional specializations) per se that pose a problem, but that they offer an appealing way to categorize the world into simplified mental models, in-group solidarities and out-group animosities that increase susceptibility to MD through dehumanization, displacement or diffusion of personal responsibility.

How might business schools address this? The empirical findings point to a need to raise awareness among students of their own moral reasoning processes. Indeed, simply raising awareness of MD by describing its processes has been found to reduce individuals' tendencies to morally disengage (Moore 2015; Baker et al. 2006; Gibson 2000). Robinson (2009, p. 11-12) argues that for a person to be fully responsible, s/he "would have to be aware of his or her social context, the significant relationships, the mutual effect of those relationships and so on." Thus, students must be encouraged to be alert to the rationalizations that they deploy in defining their responsibility, and to reflect on their personal fallibility and the limits of their own moral autonomy (Freeman and Laasch 2020). They must also be urged to take a critical 
stance towards the ingrained beliefs of their disciplinary ingroups-not just those of out-groups-and to reflect on the fact that in-group identifications which may seem highly appealing due to "the force of solidarity" can erode personal responsibility (Godwyn 2015, p. 3) due to the phenomenon of depersonalization. As Bivins (2006, p. 31) notes, "Unless we understand our real reasons, we will be content to rationalize our actions by using other means- most often adopting moral excuses or assigning the blame to others." To enhance such an awareness, business educators could, as Baker et al. (2006, p. 5) suggests, discuss MD mechanisms explicitly and critically with students in order to sensitize them to these 'otherwise unconscious cognitive processes' (see also Hummel et al. 2018) and encourage them to relate these critically to their own disciplinary prototypes and identifications. Godwyn $(2015$, p. 3) proposes that "critical thinking is the best defense against blind obedience to social convention and to the compelling, almost irresistible, force of solidarity"-although here again there is a danger that, as Bustamante and Chaux (2014, p. 55) warn, it is "easier to apply critical thinking to what others do than to what one does [oneself].' However, empirical research does suggest that classroom interventions fostering critical thinking can reduce MD by encouraging students to question the justifications that facilitate MD (Bustamante and Chaux 2014). Thus, through explicitly examining students' disciplinary perceptions and identifications in the classroom, a critical distance may be opened up that enables them to recognize when they are susceptible to being thus influenced, and to assume personal responsibility, if called for (Godwyn 2015).

Pedagogical interventions could also explicitly address the powerful influence of group dynamics on individual identity, notably the mechanism of depersonalization that can lead to a shift in the level of responsibility focus, and possible overriding of an individual's own moral standards. Such interventions might raise awareness about resulting tendencies to cast others as bad apples (but not oneself), and to 'dehumanize' others as a result of in-group identification and out-group othering. Bandura (1999, p. 200) notes that the "personalization of responsibility and humanization of others together have a powerful self-restraining effect," making it less likely that people will resort to justifications to exonerate themselves. Initiatives could therefore be designed that build cross-specialization solidarity among students, for instance by engaging them in collaborative, cross-degree, societally- and problem-oriented projects with shared goals that can enhance their awareness of the blind spots, as well as the unique insights, that characterize their own and other specializations with regard to responsibility issues. This could help to loosen up discipline-based solidarities and animosities (see also Kreber 2010) and enable students from different specializations to relate to each other as individuals forming part of a broader community (see
Gröschl and Gabandon 2018 for examples of ways to do this). Such silo-bridging initiatives have proven effective in companies plagued by "huge chasms between different functions" (Wind 2009, p. 31). Business schools could also explore ways to render disciplinary boundaries more porous by explicitly and critically discussing, with students, their perceptions of disciplinary prototypes, and the mental models, identifications and behaviors they foster. The business ethics curriculum would be an obvious area in which to conduct such activities, with a view to supporting a "holistic understanding ... [and offering] a legitimate place of alternative thinking" (Sims and Brinkmann 2003, p. 69).

The findings also indicate a need to raise students' awareness of the possible tensions that may arise between personal and professional identities in relation to responsibility, and that it may not always be possible-or wise- to fully integrate these identities when it comes to ethical issues (Minnameier 2014, p. 58). Although personal responsibility is crucial in assuring healthy professions and corporations (Robinson 2009), Colby and Sullivan (2009, p. 22) note the generally scarce institutional investment, in higher education, in students' personal responsibility which, they posit, reflects a 'widespread assumption that academic content knowledge and the intellectual skill of analytic or critical thinking, quite divorced from either action or responsibility, are the overriding aims of higher education...". In order to address this deficit, we need far more knowledge about students' sense of personal responsibility upon entering business school 'so that we can make informed decisions about providing educational experiences that may alter their perspectives' (Baker et al. 2006, p. 5). We also need to focus teaching more on how students rationalize about responsibility issues and dilemmas that concern them during their studies, instead of focusing mainly on future hypothetical moral dilemmas in professional situations, for instance through cases or simulations (Treviño and McCabe 1994), since students may find it difficult to make connections between their immediate life experiences and what they learn about in ethics courses (Gu and Neesham 2014) in relation to their personal responsibility. Also, the findings suggest a need to balance the use of teaching cases that emphasize others' (for instance firms') irresponsible behavior, with cases or examples that address misconduct by those whom students consider to be in-groups, for instance reputed national firms; and/or among the students themselves and their in-groups.

Finally, the findings point to a need to address the ubiquitous division - and hierarchy—between hard/pure disciplines and soft/applied specializations at business schools (see also Andrews and Higson 2008; Loo 2002). The findings, especially among students from harder specializations, reflect what Massey (1999, pp. 8-9) refers to as economics' "self-conceit" of being more scientific than other disciplines, highlighting a common tendency "simply to 'believe' 
economics texts" which is shared by business students unless directly prodded to critique them (cf. Watson 1996). Rather than accepting the assumed pre-eminence of economics, however, Massey (1999, p. 9) recommends that "we should be actively engaged in deconstructing it." This is paramount, since, as Jackson (2010, p. 739) notes, the roots of the current financial crisis are to be found exactly in "technocratic and dehumanized economic thinking." However, my data also indicate that students identifying with softer specializations are equally susceptible to 'disciplinary hubris' as students identifying with harder disciplines. Teachers should therefore take care to avoid reinforcing disciplinary silos of any kind by talking down other specializations or reifying hard/soft dichotomies and hierarchies. In my experience, such disciplinary othering, which involves "a distantiation between self and other," can become malign if it comes across as-albeit unintentionally-derogatory (Winiwarter 2018, p. 94; see also Becher and Trowler 2001). Kreber (2010, p. 24) suggests that making students aware of how disciplines function, notably the tacit knowledge and values that are acquired during disciplinary socialization, may be empowering for students, and "enhance their ability to tackle new problems independently." Challenging, together with students, the essentialist assumptions and often blatant power hierarchies associated with disciplines would support this critical awareness, notably that disciplines are not "abstract entities ... [but] become apparent in their playing out in the world, in the process of institutionalization and in the discursive and other practices which give them substance" (Trowler 2014, p. 1721).

\section{Conclusion}

Scholars have long debated how, and under which conditions, people make unethical decisions (Kish-Gephart et al. 2010). Identifying the role played by the business school learning environment in developing or stymying students' moral reasoning is crucial if we are to strengthen responsibility learning efforts in a meaningful way, notably under the aegis of PRME. This study contributes to this by highlighting the role played by disciplinary specializations in moral reasoning processes and discussing the implications for students' sense of personal responsibility. It also has implications for ethical business practices more broadly, since learned, disciplinary-based rationalizations for MD may influence the way students make (un)ethical decisions later on in their working lives. The study offers a theoretical framework that combines Bandura's theory of moral disengagement with social identity theory to show how students' perceptions of, and identifications with, their disciplinary specializations can provide rationalizations for the a priori disengagement of their sense of responsibility. The framework is potentially more broadly applicable to analyzing how professional in-group/out-group dynamics interplay with responsibility rationalizations and moral (dis)engagement in workplaces.

The study identified four main rationalizations enabling students to disengage their personal responsibility: (i) "responsibility is not relevant to the discipline/specialization"; (ii) "responsibility is already embedded in the discipline/specialization" and (iii) "our specialization is more responsible than X specialization"; (iv) a cross-cutting rationalization that responsibility is a matter of individual moral agency, and that 'bad apples' (others, not themselves) are largely to blame for irresponsible behavior. Combined, these rationalizations allowed students variously to displace responsibility away from their own disciplinary specializations; to claim responsibility as the prerogative of their disciplines/disciplinary in-groups; and to shift irresponsibility onto disciplinary out-groups or "bad apples." Seen from this perspective, a seemingly innocuous statement such as "we're just geeks" can signal a delimitation and deflection of personal responsibility among students identifying themselves thus.

The implications for business ethics include the need to enhance students' 'disciplinary reflexivity,' that is, their critical awareness of their own disciplinary identifications, and of their related rationalizations regarding responsibility. Business schools should also turn a critical eye to the types of disciplinary attachments that they foster; and address the tension between these and students' implicit faith in their own moral righteousness and perceived autonomy from contextual factors when it comes to responsibility. From a teaching perspective, the challenge for business schools is how to foster disciplinary identifications and a sense of professional responsibility without undermining students' sense of personal responsibility, and without fostering counterproductive forms of specialization-based solidarity that can lead to silo mentalities and collective MD. As Ottewill et al. (2005, p. 92) note, "While specialization is clearly desirable in certain situations, for business education differentiation can be counterproductive in a learning environment where what divides takes precedence over what unites". Therefore, in designing responsibility initiatives, business schools should ensure that students are aware of the need to attend to different levels of responsibility: individual, specialization-based, and collective (e.g., societal) responsibility beyond their own in-groups, and of the fact that these levels may sometimes conflict with one another. This could help ensure that students develop towards systematically and autonomously questioning personal, contextual and societal beliefs about responsibility, in line with Kohlberg's (1969) post-conventional level of moral reasoning.

To address this, first, business schools need to raise students' awareness of the limits of their personal moral agency, 
especially of their own fallibility when confronted with contextual factors, including the appeal of discipline-based solidarity, when it comes to rationalizations and decisions about responsibility. Ultimately, that means that finding ways to teach students, as future employees, to 'self-responsibilize' (Freeman and Laasch 2020, p. 116) so that they learn to take personal responsibility even in situations when they do not consider that it is theirs to take, and when "group influences discourage it" (Baker 2014, p. 520); and to raise their awareness that refusing to take responsibility is "both a denial of responsibility and a giving of responsibility to others' (Robinson 2009, p. 15).

Further research might explore whether how disciplinary prototypes are communicated and learned at business schools; why some students appear to identify more with their specializations than others; and whether business students' individual traits and demographic characteristics (such as age, gender, ethnicity) affect their disciplinary rationalizations. Studies might also explore whether business students' allegedly lower levels of moral identity predispose them more to disciplinary-based MD than other types of students; how disciplinary identity formation develops at business schools across the three years of undergraduate study, and whether there are individual differences in the degree to which students identify with disciplines. Finally, future research might examine how students negotiate disciplinary perceptions and identifications in focus-group discussions; whether and how disciplinary prototypes and identifications persist, or resurface in different forms, once students reach the workplace (this could be done by following graduate trajectories), and the implications of this for moral disengagement.

Supplementary Information The online version of this article (https:// doi.org/10.1007/s10551-021-04759-7) contains supplementary material, which is available to authorized users.

\section{Compliance with Ethical Standards}

Conflict of interest I declare that the manuscript complies with the ethical standards for good scientific practice outlined in the J Business Ethics. I declare no conflict of interest in connection with this manuscript.

Open Access This article is licensed under a Creative Commons Attribution 4.0 International License, which permits use, sharing, adaptation, distribution and reproduction in any medium or format, as long as you give appropriate credit to the original author(s) and the source, provide a link to the Creative Commons licence, and indicate if changes were made. The images or other third party material in this article are included in the article's Creative Commons licence, unless indicated otherwise in a credit line to the material. If material is not included in the article's Creative Commons licence and your intended use is not permitted by statutory regulation or exceeds the permitted use, you will need to obtain permission directly from the copyright holder. To view a copy of this licence, visit http://creativecommons.org/licenses/by/4.0/.

\section{References}

Andrews, J., \& Higson, H. (2008). Graduate employability, 'soft skills' versus 'hard' business knowledge: a European study. High Educ Eur, 33(4), 411-422.

Antonacopoulou, E. P. (2010). Making the business school more "critical': reflexive critique based on phronesis as a foundation for impact. British Journal of Management, 21, 6-25.

Archer, J., \& Freedman, S. (1989). Gender-stereotypic perceptions of academic disciplines. British Journal of Educational Psychology, 59(3), 306-313.

Ashforth, B. E., \& Mael, F. (1989). Social identity theory and the organization. Academy of Management Review, 14(1), 20-39.

Atwater, J. B., Kannan, V. R., \& Stephens, A. A. (2008). Cultivating systemic thinking in the next generation of business leaders. Acad Manag Learn Educ, 7(1), 9-25.

Baker, D. F. (2014). When moral awareness isn't enough: teaching our students to recognize social influence. J Manag Educ, 38(4), 511-532.

Baker VL, Detert JR, Treviño LK (2006) MD in business school students: predictors and comparisons. In: Academy of management proceedings, No. 1, pp. H1-H6. Academy of Management, Briarcliff Manor

Bandura, A. (1999). MD in the perpetration of inhumanities. Person Soc Psychol Rev, 3(3), 193-209.

Bandura, A. (2016). MD: How people do harm and live with themselves. New York: Worth Publishers.

Bandura, A., Barbaranelli, C., Caprara, G. V., \& Pastorelli, C. (1996). Mechanisms of MD in the exercise of moral agency. J Person Soc Psychol, 71(2), 364.

Bandura, A., Caprara, G. V., \& Zsolnai, L. (2000). Corporate transgressions through MD. J Hum Values, 6(1), 57-64.

Bansal, P., \& Kandola, S. (2003). Corporate social responsibility: why good people behave badly in organizations. Ivey Business $J, 67(4), 1-5$.

Barsky, A. (2011). Investigating the effects of MD and participation on unethical work behavior. J Business Ethics, 104(1), 59.

Becher, T., \& Trowler, P. (2001). Academic tribes and territories: Intellectual enquiry and the culture of disciplines (2nd ed.). Buckingham: The Society for Research into Higher Education and Open University Press.

Becker, G. K. (2018). Moral leadership in business. In W. E. Rosenbach (Ed.), Contemporary issues in leadership (pp. 237-257). New York: Routledge.

Bian, J., Li, L., Sun, J., Deng, J., Li, Q., Zhang, X., \& Yan, L. (2019). The influence of self-relevance and cultural values on moral orientation. Front Psychol, 10, 292.

Biglan, A. (1973). The characteristics of subject matter in different academic areas. Journal of Applied Psychology, 57, 195-203.

Bivins, T. H. (2006). Responsibility and accountability. In K. Fitzpatrick \& C. Bronstein (Eds.), Ethics in public relations: responsible advocacy (pp. 19-38). Thousand Oaks, CA: Sage.

Blair, J., \& Fowler, K. (2008). Moral emotions and moral reasoning from the perspective of affective cognitive neuroscience: a selective review. Int J Dev Sci, 2(3), 303-323.

Blasco, M. (2012). Aligning the hidden curriculum of management education with PRME: an inquiry-based framework. J Manag Educ, 36(3), 364-388.

Blasco, M. (2020). The hidden curriculum: can the concept support responsible management learning? (pp. 459-482). London: The SAGE Handbook of Responsible Management Learning and Education. SAGE Publications.

Brand, V. (2009). Empirical business ethics research and paradigm analysis. J Business Ethics, 86(4), 429-449. 
Brinkmann, S. (2013). Qualitative interviewing. Oxford: Oxford University Press.

Brockett, R. G., \& Hiemstra, R. (1991). Self-direction in adult learning: perspectives on theory, research, and practice. London: Routledge.

Brubaker, R. (2004). Ethnicity without groups. Cambridge, MA: Harvard University Press.

Bustamante, A., \& Chaux, E. (2014). Reducing moral disengagement mechanisms: a comparison of two interventions. J Latino Am Stud, 6(1), 52-54.

Caldwell, C. (2010). A ten-step model for academic integrity: a positive approach for business schools. J Business Ethics, 92(1), 1-13.

Campbell, D., \& Cowton, C. J. (2015). Method issues in business ethics research: finding credible answers to questions that matter. Business Ethics, 24, 3-10.

Card, R. F. (2005). Individual responsibility within organizational contexts. J Business Ethics, 62(4), 397-405.

Cartwright, S., \& Cooper, C. L. (1995). Organizational marriage: "hard" versus "soft" issues? Person Rev, 24(3), 32-42.

Chiu, C. Y., Morris, M. W., Hong, Y. Y., \& Menon, T. (2000). Motivated cultural cognition: the impact of implicit cultural theories on dispositional attribution varies as a function of need for closure. J Person Soc Psychol, 78(2), 247.

Colbeck, C. L. (2008). Professional identity development theory and doctoral education. New Directions Teach Learn, 113, 9-16.

Colby, A., \& Sullivan, W. M. (2009). Strengthening the foundations of students' excellence, integrity, and social contribution. Liberal Educ, 95(1), 22-29.

Cooper, D. J., Everett, J., \& Neu, D. (2005). Financial scandals, accounting change and the role of accounting academics: a perspective from North America. Eur Account Rev, 14(2), 373-382.

Crigger, N., \& Godfrey, N. (2014). From the inside out: a new approach to teaching professional identity formation and professional ethics. Journal of Professional Nursing, 30(5), 376-382.

Cunliffe, A. L., \& Eriksen, M. (2011). Relational leadership. Hum Relations, 64(11), 1425-1449.

Czarniawska, B. (2008). Alterity/identity interplay in image construction (pp. 49-62). Sage, Thousand Oaks, CA: The SAGE handbook of new approaches in management and organization.

De los Reyes, G., Kim, T. W., and Weaver, G. R. . (2017). Teaching ethics in business schools: a conversation on disciplinary differences, academic provincialism, and the case for integrated pedagogy. Acad Manag Learn Educ, 16(2), 314-336.

Detert, J. R., Treviño, L. K., \& Sweitzer, V. L. (2008). MD in ethical decision making: a study of antecedents and outcomes. Journal of Applied Psychology, 93(2), 374-391.

Doyle, E., \& O'Flaherty, J. (2013). The impact of education level and type on moral reasoning. Irish Educ Stud, 32(3), 377-393.

Ehrensal, K. N. (2001). Training capitalism's foot soldiers: the hidden curriculum of undergraduate business education. In E. Margolis (Ed.), The hidden curriculum in higher education (pp. 97-113). New York: Routledge.

Elo, S., Kääriäinen, M., Kanste, O., Pölkki, T., Utriainen, K., \& Kyngäs, H. (2014). Qualitative content analysis. SAGE Open, 4, 1.

Escudero M, Csuri M, Alcaraz JM, Goldberg ES, Guevara R, Howaidy G (2015) Transformational model for PRME implementation. http://www.unprme.org/resource-docs/PRMETransformational Web.pdf. Accessed 25 June 2019

Fanghanel, J. (2009). The role of ideology in shaping academics' conceptions of their discipline. Teach High Educ, 14(5), 565-577.

Farnese, M. L., Tramontano, C., Fida, R., \& Paciello, M. (2011). Cheating behaviors in academic context: does academic MD matter? Proc Soc Behav Sci, 29, 356-365.

Felton, E. L., \& Sims, R. R. (2005). Teaching business ethics: targeted outputs. J Business Ethics, 60(4), 377-391.
Fida, R., Tramontano, C., Paciello, M., Ghezzi, V., \& Barbaranelli, C. (2018). Understanding the interplay among regulatory selfefficacy, MD, and academic cheating behavior during vocational education: a three-wave study. J Business Ethics, 153(3), $725-740$

Floyd, L. A., Xu, F., Atkins, R., \& Caldwell, C. (2013). Ethical outcomes and business ethics: toward improving business ethics education. J Business Ethics, 117(4), 753-776.

Forray, J., Leigh, J., \& Kenworthy, A. L. (2015). Special section cluster on responsible management education: nurturing an emerging PRME ethos. Acad Manag Learn Educ, 14(2), 293-296.

Frederick, W. C., \& Swanson, D. L. (2017). Are business schools silent partners in corporate crime? Business, capitalism and corporate citizenship (pp. 84-89). London: Routledge.

Freeman, R. E., \& Laasch, O. (2020). From management sucks to responsible management rocks! Research handbook of responsible management. Cheltenham: Edward Elgar Publishing.

Ghoshal, S. (2003). Musings: business schools share the blame for enron. Business Ethics, 17(3), 4.

Ghoshal, S. (2005). Bad management theories are destroying good management practices. Acad Manag Learn Educ, 4(1), 75-91.

Giacalone, R. A., \& Thompson, K. R. (2006). Business ethics and social responsibility education: shifting the worldview. Acad Manag Learn Educ, 5(3), 266-277.

Gibson, K. (2000). Excuses, excuses: moral slippage in the workplace. Business Horizons, 43(6), 65-65.

Gilligan, C. (1982). In a different voice: psychological theory and women's development. Cambridge, MA: Harvard University Press.

Gioia, D. A., Corley, K. G., \& Hamilton, A. L. (2013). Seeking qualitative rigor in inductive research: notes on the Gioia methodology. Org Res Methods, 16(1), 15-31.

Glaser-Segura, D. A., Mudge, S., Brătianu, C., \& Dumitru, I. (2010). Development of professional identity in Romanian business students. Educ Train, 52(3), 198-213.

Godwyn, M. (2015). Ethics and diversity in business management education: a sociological study with international scope. Berlin: Springer.

Gresalfi, M. S., \& Cobb, P. (2006). Cultivating students' disciplinespecific dispositions as a critical goal for pedagogy and equity. Pedagogies, 1(1), 49-57.

Grey, C. (2002). What are business schools for? On silence and voice in management education. J Manag Educ, 26(5), 496-511.

Grinyer, A. (2009). The ethics of the secondary analysis and further use of qualitative data. Soc Res Update, 56(4), 1-4.

Gröschl, S., \& Gabaldon, P. (2018). Business schools and the development of responsible leaders: a proposition of Edgar Morin's transdisciplinarity. J Business Ethics, 153(1), 185-195.

Gu, J., \& Neesham, C. (2014). Moral identity as leverage point in teaching business ethics. J Business Ethics, 124(3), 527-536.

Hammersley, M., \& Traianou, A. (2012). Ethics in qualitative research: controversies and contexts. London: Sage.

Hanson, W. R., \& Moore, J. R. (2014). Business student moral influencers: unseen opportunities for development? Acad Manag Learn Educ, 13(4), 525-546.

Harris, J. D., \& Freeman, R. E. (2008). The impossibility of the separation thesis: a response to Joakim Sandberg. Business Ethics $Q$, 18(4), 541-548.

Haski-Leventhal, D., Pournader, M., \& McKinnon, A. (2017). The role of gender and age in business students' values, CSR attitudes, and responsible management education: learnings from the PRME international survey. J Business Ethics, 146(1), 219-239.

Hawtrey, K., \& Johnson, R. (2010). On the atrophy of moral reasoning in the global financial crisis. J Religion Business Ethics, 1(2), $1-24$.

Hiemstra, R. (1994). Helping learners take responsibility for selfdirected activities. In R. Hiemstra \& R. G. Brockett (Eds.), 
Overcoming resistance to self-direction in adult learning (New Directions for Adult and Continuing Education, No 64 (pp. 81-87). San Francisco, CA: Jossey-Bass.

Hiemstra, R., \& Brockett, R. G. (1994). Resistance to self-direction in learning can be overcome. New Directions Adult Contin Educ, 64, 89-92.

Hogg, M. A., Terry, D. J., \& White, K. M. (1995). A tale of two theories: a critical comparison of identity theory with social identity theory. Soc Psychol Q, 58, 255-269.

Hogg, M. A., \& Reid, S. A. (2006). Social identity, self-categorization, and the communication of group norms. Commun Theory, 16(1), 7-30.

Hornsey, M. J. (2008). Social identity theory and self-categorization theory: a historical review. Soc Person Psychol Compass, 2(1), 204-222.

Hummel, K., Pfaff, D., \& Rost, K. (2018). Does economics and business education wash away moral judgment competence? J Business Ethics, 150(2), 559-577.

Hyland, K. (2012). Disciplinary identities: individuality and community in academic discourse. Cambridge: Cambridge University Press.

Irwin, S. (2013). Qualitative secondary data analysis: ethics, epistemology and context. Prog Dev Stud, 13(4), 295-306.

Jackson, K. T. (2010). The scandal beneath the financial crisis: getting a view from a moral-cultural mental model. Harv JL Pub Pol'y, 33,735 .

Jenkins, R. (2014). Social identity. London: Routledge.

Johnson, J. F., \& Connelly, S. (2016). MD and ethical decisionmaking. J Person Psychol, 15(4), 184-189.

Jones, T. M. (1991). Ethical decision making by individuals in organizations: an issue-contingent model. Academy of Management Review, 16, 366-395.

Jones, N. A., Ross, H., Lynam, T., Perez, P., \& Leitch, A. (2011). Mental models: an interdisciplinary synthesis of theory and methods. Ecol Soc, 16(1), 46.

Kavussanu, M. (2008). Moral behavior in sport: a critical review of the literature. Int Rev Sport Exer Psychol, 1(2), 124-138.

Khurana, R. (2010). Fom higher aims to hired hands: the social transformation of American Business Schools and the unfulfilled promise of management as a profession. Princeton, NJ: Princeton University Press.

Khurana, R., \& Spender, J. C. (2012). Herbert A. Simon on what ails business schools: more than 'a problem in organizational design.' J Manag Stud, 49(3), 619-639.

Kish-Gephart, J. J., Harrison, D. A., \& Treviño, L. K. (2010). Bad apples, bad cases, and bad barrels: meta-analytic evidence about sources of unethical decisions at work. Journal of Applied Psychology, 95(1), 1-31.

Klein, H. A., Levenburg, N. M., McKendall, M., \& Mothersell, W. (2007). Cheating during the college years: how do business school students compare? J Business Ethics, 72, 2.

Kogan, M. (2005). Modes of knowledge and patterns of power. Higher Education, 49(1-2), 9-30.

Kohlberg, L. (1969). Stage and sequence: the cognitive-developmental approach to socialization. In D. A. Goslin (Ed.), The handbook of socialization theory and research (pp. 347-480). Chicago: Rand McNally.

Koris, R., Örtenblad, A., \& Ojala, T. (2017). From maintaining the status quo to promoting free thinking and inquiry: business students' perspective on the purpose of business school teaching. Manag Learn, 48(2), 174-186.

Kreber, C. (2010). The university and its disciplines: teaching and learning within and beyond disciplinary boundaries. Oxford: Routledge.
Krueger, R. A. (1998). Analysis considerations for focus group research. Focus Group kit:analyzing and reporting focus group (pp. 31-38). Thousand Oaks, CA: Sage.

Krueger, R. A., \& Casey, M. A. (2014). Focus groups: a practical guide for applied research. Thousand Oaks, CA: Sage.

Kulis, S., Sicotte, D., \& Collins, S. (2002). More than a pipeline problem: labor supply constraints and gender stratification across academic science disciplines. Research in Higher Education, 43(6), 657-691.

Laasch O (2018) Just old wine in new bottles? Conceptual shifts in the emerging field of responsible management. CRME Working Papers, 4(1)

Lampe, M., \& Engleman-Lampe, C. (2012). Mindfulness-based business ethics education. Acad Educ Leadership J, 16(3), 99-111.

Lämsä, A. M., Vehkaperä, M., Puttonen, T., \& Pesonen, H. L. (2008). Effect of business education on women and men students' attitudes on corporate responsibility in society. J Business Ethics, $82(1), 45-58$.

Lawler, S. (2008). Identity: sociological perspectives. Cambridge: Polity Press.

Lee, B., \& Aslam, U. (2018). Towards the wholesome interview: technical, social and political dimensions. In C. Cassell, A. L. Cunliffe, \& G. Grandy (Eds.), The SAGE Handbook of Qualitative Business and Management Research Methods. Thousand Oaks: Sage.

Loo, R. (2002). The distribution of learning styles and types for hard and soft business majors. Educ Psychol, 22(3), 349-360.

Macfarlane, B. (1995). Business and management studies in higher education: the challenge of academic legitimacy. Int $J$ Educ Manag, 9(5), 4-9.

McNamee, S., \& Gergen, K. J. (1999a). Relational responsibility: resources for sustainable dialogue. Thousand Oaks, CA: Sage.

Massey, D. (1999). Negotiating disciplinary boundaries. Curr Sociol, 47(4), 5-12.

McAlister, A. L., Bandura, A., \& Owen, S. V. (2006). Mechanisms of moral disengagement in support of military force: the impact of Sept 11. Journal of Social and Clinical Psychology, 25(2), 141-1651.

McCabe, D. L., \& Treviño, L. K. (1995). Cheating among business students: a challenge for business leaders and educators. J Manag Educ, 19(2), 205-218.

McCabe, D. L., Butterfield, K. D., \& Treviño, L. K. (2012). Cheating in college: why students do it and what educators can do about it. Baltimore: The Johns Hopkins University Press.

McIntosh, M. (Ed.). (2017). Business, capitalism and corporate citizenship: a collection of seminal essays. London: Routledge.

McNamee, S., \& Gergen, K. J. (1999b). Relational responsibility: resources for sustainable dialogue. Thousand Oaks: Sage.

McPhail, K., \& Walters, D. (2009). Accounting and business ethics: An introduction. London: Routledge.

Milgram, S. (1963). Behavioral study of obedience. Journal of Abnormal and Social Psychology, 67(4), 371-376.

Milgram, S. (1974). Obedience to authority. New York: Harper and Row.

Miller, J. G., \& Bersoff, D. M. (1992). Culture and moral judgment: how are conflicts between justice and interpersonal responsibilities resolved? J Person Soc Psychol, 62(4), 541-554.

Minnameier, G. (2014). Moral aspects of professions and professional practice. International handbook of research in professional and practice-based learning (pp. 57-77). Dordrecht: Springer.

Mitroff, I. I. (2004). An open letter to the deans and the faculties of American business schools. J Business Ethics, 54, 185-189.

Moore, C. (2008). MD in processes of organizational corruption. $J$ Business Ethics, 80(1), 129-139. 
Moore, C., Detert, J. R., Klebe Treviño, L., Baker, V. L., \& Mayer, D. M. (2012). Why employees do bad things: MD and unethical organizational behavior. Person Psychol, 65(1), 1-48.

Moore, C. (2015). MD. Curr Opin Psychol, 6, 199-204.

Moosmayer, D. C. (2012). A model of management academics' intentions to influence values. Acad Manag Learn Educ, 11(2), $155-173$.

Morrow, V., Boddy, J., \& Lamb, R. (2014). The ethics of secondary data analysis: Learning from the experience of sharing qualitative data from young people and their families in an international study of childhood poverty. Sussex: University of Sussex.

Morgan, D. L. (1988). Focus groups as qualitative research. London: Sage.

Morgan, D. L. (1997). Focus groups as qualitative research (2nd ed.). Thousand Oaks, CA: Sage.

Narvaez, D., Getz, I., Rest, J. R., \& Thoma, S. J. (1999). Individual moral judgment and cultural ideologies. Developmental Psychology, 35(2), 478.

Nather, F. (2013). Exploring the impact of formal education on the moral reasoning abilities of college students. College Stud J, 47(3), 470-477.

Neubaum, D. O., Pagell, M., Drexler, J. A., Jr., Mckee-Ryan, F. M., \& Larson, E. (2009). Business education and its relationship to student personal moral philosophies and attitudes toward profits: an empirical response to critics. Acad Manag Learn Educ, 8(1), 9-24.

Onwuegbuzie, A. J., Dickinson, W. B., Leech, N. L., \& Zoran, A. G. (2009). A qualitative framework for collecting and analyzing data in focus group research. Int J Qual Methods, 8(3), 1-21.

Orton, J. D. (1997). From inductive to iterative grounded theory: zipping the gap between process theory and process data. Scandinavian Journal of Management, 13(4), 419-438.

Ottewill, R., McKenzie, G., \& Leah, J. (2005). Integration and the hidden curriculum in business education. Educ Train, 47(2), 89-97.

Paciello, M., Fida, R., Tramontano, C., Lupinetti, C., \& Caprara, G. V. (2008). Stability and change of moral disengagement and its impact on aggression and violence in late adolescence. Child Development, 79(5), 1288-1309.

Parker, M. (2018). Shut down the business school. London: Pluto Press.

Piaget, J. (1932). The moral judgment of the child. Glencoe: Free Press.

Podolny, J. M. (2009). The buck stops (and starts) at business school. Harvard Business Rev, 87(6), 62-67.

Rajeev, P. N. (2011). Exploring moral action: a critical review of integrative models and suggestions for future research. J Int Business Ethics, 4, 2.

Rest, J. R. (1986). Moral development: advances in research and theory. New York: Praeger.

Rest, J., Thoma, S., \& Edwards, L. (1997). Designing and validating a measure of moral judgment: stage preference and stage consistency approaches. Journal of Educational Psychology, 89(1), $5-28$.

Riordan, D., \& Riordan, M. (2013). Guarding against groupthink in the professional work environment: a checklist. J Acad Business Ethics, 7, 1-8.

Robinson, S. (2009). The nature of responsibility in a professional setting. J Business Ethics, 88(1), 11-19.

Robinson, M., \& Murphy, D. (2009). Greed is good: maximization and elite deviance in America. Lanham: Rowman and Littlefield.

Sarangapani, P. M. (2011). Soft disciplines and hard battles. Contemp Educ Dialog, 8(1), 67-84.

Schein, E. H. (2010). Organizational culture and leadership. New York: Wiley.

Schlenker, B. R., Miller, M. L., \& Johnson, R. M. (2009). Moral identity, integrity, and personal responsibility (pp. 316-340).
Cambridge: Personality, Identity, and Character: Explorations in Moral Psychology. Cambridge University Press.

Schreier, M. (2012). Qualitative content analysis in practice. Thousand Oaks, CA: Sage.

Schommer-Aikins, M., Duell, O. K., \& Barker, S. (2003). Epistemological beliefs across domains using Biglan's classification of academic disciplines. Research in Higher Education, 44(3), $347-366$.

Seale, C., \& Silverman, D. (1997). Ensuring rigour in qualitative research. European Journal of Public Health, 7(4), 379-384.

Semper, J. V. O., \& Blasco, M. (2018). Revealing the hidden curriculum in higher education. Studies in Philosophy and Education, 37(5), 481-498.

Serrat, O. (2017). Bridging organizational silos. Knowledge solutions (pp. 711-716). Singapore: Springer.

Silva, F. N., Rodrigues, F. A., Oliveira, O. N., Jr., \& Costa, L. D. F. (2013). Quantifying the interdisciplinarity of scientific journals and fields. J Inf, 7(2), 469-477.

Sim, J. (1998). Collecting and analyzing qualitative data: issues raised by the focus group. Journal of Advanced Nursing, 28(2), $345-352$.

Sims, R. R., \& Brinkmann, J. (2003). Enron ethics (or: culture matters more than codes). J Business Ethics, 45(3), 243-256.

Smith, E., \& Smith, J., Jr. (2008). Using secondary data in educational and social research. UK: McGraw-Hill Education.

Solitander, N., Fougère, M., Sobczak, A., \& Herlin, H. (2012). We are the champions: organizational learning and change for responsible management education. J Manag Educ, 36(3), 337-363.

Sonnert, G., \& Commons, M. L. (1992). Society and the highest stages of moral development. Polit Individual, 4(1), 31-55.

Stebbins, R. A. (2001). Exploratory research in the social sciences (Vol. 48). Thousand Oaks, CA: Sage.

Stets, J. E., \& Burke, P. J. (2000). Identity theory and social identity theory. Soc Psychol Q, 3, 224-237.

Stewart DW, Shamdasani PN, Rook DW (1990) Analyzing focus group data. In: Focus groups: Theory and practice, pp 102-121

Sykes, G. M., \& Matza, D. (1957). Techniques of neutralization: a theory of delinquency. Am Soc Rev, 22(6), 664-670.

Swaner, L. E. (2005). Educating for personal and social responsibility: a review of the literature. Liberal Educ, 91(3), 14-21.

Tajfel H (1972) Social categorization. English manuscript of " La categorisation sociale.’ In: S. Moscovici (Ed.) Introduction à la psychologie sociale, Vol 1, pp 272-302. Larousse, Paris

Thomas, S. (2012). Ethics and accounting education. Issues Account Educ, 27(2), 399-418.

Thomson, K., \& Jones, J. (2017). Precarious professionals: (in) secure identities and moral agency in neocolonial context. $J$ Business Ethics, 146(4), 747-770.

Trede, F., Macklin, R., \& Bridges, D. (2012). Professional identity development: a review of the higher education literature. Stud High Educ, 37(3), 365-384.

Treviño, L. K. (1992). Moral reasoning and business ethics: implications for research, education, and management. J Business Ethics, 11(5-6), 445-459.

Treviño, L. K., \& McCabe, D. (1994). Meta-learning about business ethics: building honorable business school communities. $J$ Business Ethics, 13(6), 405-416.

Treviño, L. K., \& Nelson, K. A. (1999). Managing business ethics: straight talk about how to do it right. New York: Wiley.

Treviño, L. K., \& Nelson, K. A. (2016). Managing business ethics: straight talk about how to do it right. New York: Wiley.

Treviño, L. K., Weaver, G. R., \& Reynolds, S. J. (2006). Behavioral ethics in organizations: a review. J Manag, 32(6), 951-990. 
Trowler, P. (2014). Depicting and researching disciplines: strong and moderate essentialist approaches. Stud High Educ, 39(10), $1720-1731$.

Turner, J. C. (1982). Towards a cognitive redefinition of the social group. Soc Identity Intergroup Relations, 1(2), 15-40.

UN PRME (2021, 7 Jan) PRME Champions. https://www.unprme.org/ prme-champions

Walden, G. R. (Ed.). (2012). SAGE Benchmarks in Social Research Methods:Focus group research. London: Sage.

Walker, L. J. (1989). A longitudinal study of moral reasoning. Child Development, 60, 157-166.

Walker, L. J. (2014). Sex differences in moral reasoning. Handb Moral Behav Dev, 2, 333-364.

Walker, L. J., de Vries, B., \& Trevethan, S. D. (1987). Moral stages and moral orientations in real-life and hypothetical dilemmas. Child Development, 58, 842-858.

Wallerstein, I., Alatas, S., Brumann, C., Calhoun, C., Hall, J., Madan, T. N., \& Wallerstein, I. (2003). Anthropology, sociology, and other dubious disciplines. Curr Anthropol, 44(4), 453-465.

Wareing, S. (2009). Disciplines, discourse and Orientalism: the implications for postgraduate certificates in learning and teaching in higher education. Stud High Educ, 34(8), 917-928.

Wark, G. R., \& Krebs, D. L. (1997). Sources of variation in moral judgment: toward a model of real-life morality. Journal of Adult Development, 4(3), 163-178.

Watson, T. J. (1996). Motivation: that's Maslow, isn't it? Manag Learn, 27(4), 447-464.

Waytz, A., \& Epley, N. (2012). Social connection enables dehumanization. Journal of Experimental Social Psychology, 48(1), 70-76.

Weaver, G. R., \& Treviño, L. K. (2015). Methodologies of business ethics research (pp. 1-5). New York: Wiley Encyclopedia of Management. Wiley.

West, C., \& Chur-Hansen, A. (2004). Ethical enculturation: the informal and hidden ethics curricula at an Australian medical school. Focus Health Prof Educ, 6(1), 85-99.

White, J., Bandura, A., \& Bero, L. A. (2009). MD in the corporate world. Account Res, 16(1), 41-74.
White, K., Carvalho, T., \& Riordan, S. (2011). Gender, power and managerialism in universities. J High Educ Policy Manag, 33(2), 179-188.

Wicks, A. C. (1996). Overcoming the separation thesis: the need for a reconsideration of business and society research. Business Soc, 35(1), 89-118.

Wilkinson, S., \& Silverman, D. (2004). Focus group research. In D. Silverman (Ed.), Qualitative research: theory, method and practice (pp. 177-199). Thousand Oaks, CA: Sage.

Wind, J. Y. (2009). Rethinking marketing: Peter Drucker's challenge. $J$ Acad Market Sci, 37(1), 28.

Winiwarter, V. (2018). The other kind of research: on the ambivalent ties between disciplinary, multi-inter-and transdisciplinary scholarship. Eur Rev, 26(2), 85-92.

$\mathrm{Xu}$, Y. J. (2008). Gender disparity in STEM disciplines: a study of faculty attrition and turnover intentions. Research in Higher Education, 49(7), 607-624.

Ylijoki, O. H. (2000). Disciplinary cultures and the moral order of studying: a case-study of four Finnish university departments. Higher Education, 39(3), 339-362.

Young, M. F. D. (2008). Bringing knowledge back in: from social constructivism to social realism in the sociology of education. London: Routledge.

Zimbardo, P. G. (1995). The psychology of evil: a situationist perspective on recruiting good people to engage in anti-social acts. Res Soc Psychol, 11, 125-213.

Zimbardo, P. (2007). The Lucifer effect: how good people turn evil. London: Rider.

Publisher's Note Springer Nature remains neutral with regard to jurisdictional claims in published maps and institutional affiliations. 